\title{
Current advances in the development of novel polymeric nanoparticles for the treatment of neurodegenerative diseases
}

Amanda Cano ${ }^{\mathrm{a}, \mathrm{b}, \mathrm{c}, *}$, Elena Sánchez-López ${ }^{\mathrm{a}, \mathrm{b}, \mathrm{c}}$, Miren Ettcheto ${ }^{\mathrm{c}, \mathrm{d}, \mathrm{e}}$, Ana López-

Machado $^{\mathrm{a}, \mathrm{b}}$, Marta Espina ${ }^{\mathrm{a}, \mathrm{b}}$, Eliana B. Souto ${ }^{\mathrm{g}, \mathrm{h}}$, Ruth Galindo ${ }^{\mathrm{a}, \mathrm{b}, \mathrm{c}, \mathrm{f}}$, Antonio Camins ${ }^{\mathrm{c}, \mathrm{d}}$, Maria Luisa García ${ }^{\mathrm{a}, \mathrm{b}, \mathrm{c}}$, Patric Turowski ${ }^{\mathrm{i}}$.

${ }^{a}$ Department of Pharmacy, Pharmaceutical Technology and Physical Chemistry, Faculty of Pharmacy and Food Sciences, University of Barcelona, Spain.

${ }^{\mathrm{b}}$ Institute of Nanoscience and Nanotechnology (IN2UB), Barcelona, Spain.

${ }^{c}$ Biomedical Research Networking Centre in Neurodegenerative Diseases (CIBERNED), Madrid, Spain.

${ }^{\mathrm{d}}$ Department of Pharmacology, Toxicology and Therapeutic Chemistry, Faculty of Pharmacy and Food Sciences, University of Barcelona, Spain.

${ }^{\mathrm{e}}$ Unit of Biochemistry and Pharmacology, Faculty of Medicine and Health Sciences, University of Rovira i Virgili, Reus (Tarragona), Spain.

${ }^{\mathrm{f}}$ Unit of Synthesis and Biomedical Applications of Peptides, Department of Biomedical Chemistry, Institute for Advanced Chemistry of Catalonia, Consejo Superior de Investigaciones Científicas (IQAC-CSIC), Barcelona, Spain.

${ }^{\mathrm{g}}$ Department of Pharmaceutical Technology, Faculty of Pharmacy, University of Coimbra,

Coimbra, Portugal.

${ }^{\mathrm{h}}$ CEB - Centre of Biological Engineering, University of Minho, Campus de Gualtar 4710057 Braga, Portugal

${ }^{\mathrm{i}}$ UCL Institute of Ophthalmology, University College of London, United Kingdom.

\section{* Corresponding author:}

Amanda Cano, Adjunct Professor of Physical Chemistry, Department of Pharmacy, Pharmaceutical Technology and Physical Chemistry, Faculty of Pharmacy and Food Sciences. Av. Joan XXIII, 27-31, 08028.

University of Barcelona, Barcelona, Spain.

E-mail address: acanofernandez@ub.edu

\section{Acknowledgements}

Authors acknowledge the support of the Spanish Ministry of Science, Innovation and Universities, Biomedical Research Networking Centre in Neurodegenerative Diseases (CIBERNED) and European Regional Development Founds. 


\title{
Abbreviations
}

6-OHDA, 6-hydroxydopamine; AA, ascorbic acid; $\mathrm{A} \beta$, amyloid- $\beta$ peptide; $\mathrm{AD}$, Alzheimer's disease; Ag, antigen; AUC, area under curve; BBB, blood-brain barrier; BCSFB, blood-cerebrospinal fluid barrier; CBZ, carbamazepine; CNS, central nervous system; DALYs, disability adjusted life-years; DBP, vitamin D-binding protein; DXI, dexibuprofen; EGCG, epigallocatechin-3-gallate; EPO, erythropoietin; HD, Huntington's disease; KA, kainic acid; MAb, monoclonal antibody; MS, multiple sclerosis; ND, neurodegenerative; NUV, neurovascular unit; OXC, oxcarbazepine; PD, Parkinson's disease; PHT, phenytoin; PNPs, polymeric nanoparticles; Pgp, P-glycoprotein; PLGA, poly(lactic-co glycolic acid); QT, quercetin; LIF, leukemia inhibitory factor; siRNAs, small interfering RNAs; RVG29, Rabies Virus Glycoprotein 29; SNCA, $\alpha$-synuclein; TH, tyrosine hydroxylase; TRH, thyrotropin releasing hormone; WHO, World Health Organization;

\section{Keywords}

Polymeric nanoparticles; brain targeting; neurodegenerative diseases; neurological diseases; brain disorders; CNS nanomedicine.

\begin{abstract}
Effective intervention is essential to combat the coming epidemic of neurodegenerative (ND) diseases. Nanomedicine can overcome restrictions of CNS delivery imposed by the blood-brain barrier (BBB), and thus be instrumental in preclinical discovery and therapeutic intervention of ND diseases. Polymeric nanoparticles (PNPs) have shown great potential and versatility to encapsulate several compounds simultaneously in controlled drug delivery systems and target them to the deepest brain regions. Here, we critically review recent advances in the development of drugs incorporated into PNPs and summarise the molecular changes and functional effects achieved in pre-clinical models of the most common ND disorders. We also briefly discuss the many challenges remaining to translate these findings and technological advances successfully to current clinical settings.
\end{abstract}




\section{INTRODUCTION}

In the last few decades, population growth and improvement of quality of life in developed countries has led to an increase in life expectancy that is closely linked to an increase in the prevalence of ND disorders [1]. Neurodegeneration is defined as progressive damage in neural tissues giving rise to irrecoverable neuronal loss. This affects the cognitive function, motor activity and mental impairment in affected individuals [2]. Neurodegeneration is associated with as a variety of disorders, such Alzheimer's disease (AD), epilepsy, Parkinson's disease (PD) and multiple sclerosis (MS), each differing in pathological patterns and clinical manifestation [3].

In 2015, the Global Burden Disease report of neurological disorders estimated that ND diseases caused around 250 million disability-adjusted life years (DALYs), which represents $10.2 \%$ of global DALYs, and 9 million (16.8\%) of global deaths (Figure 1) [4]. Moreover, this study also reported that there was a large increase of the absolute numbers of DALYs, deaths, and prevalent cases of different dementias, even though the age-standardised rates changes were smallest [4]. The latest data from the World Health Organization (WHO) reported that, 47.5 million people currently suffer from dementia, with 7.7 million new cases being diagnosed every year [5]. Epileptic disorders exhibit a stable age-standardized prevalence rate accompanied by a significant decrease in deaths and DALY rates. For PD, the age-standardized rates are modest, whereas the numbers of prevalent cases, DALYs and deaths have significantly increased. In turn for MS, available data shows decreasing age-standardized rates while prevalent cases, DALYs and deaths increase (Figure 1) [4]. 


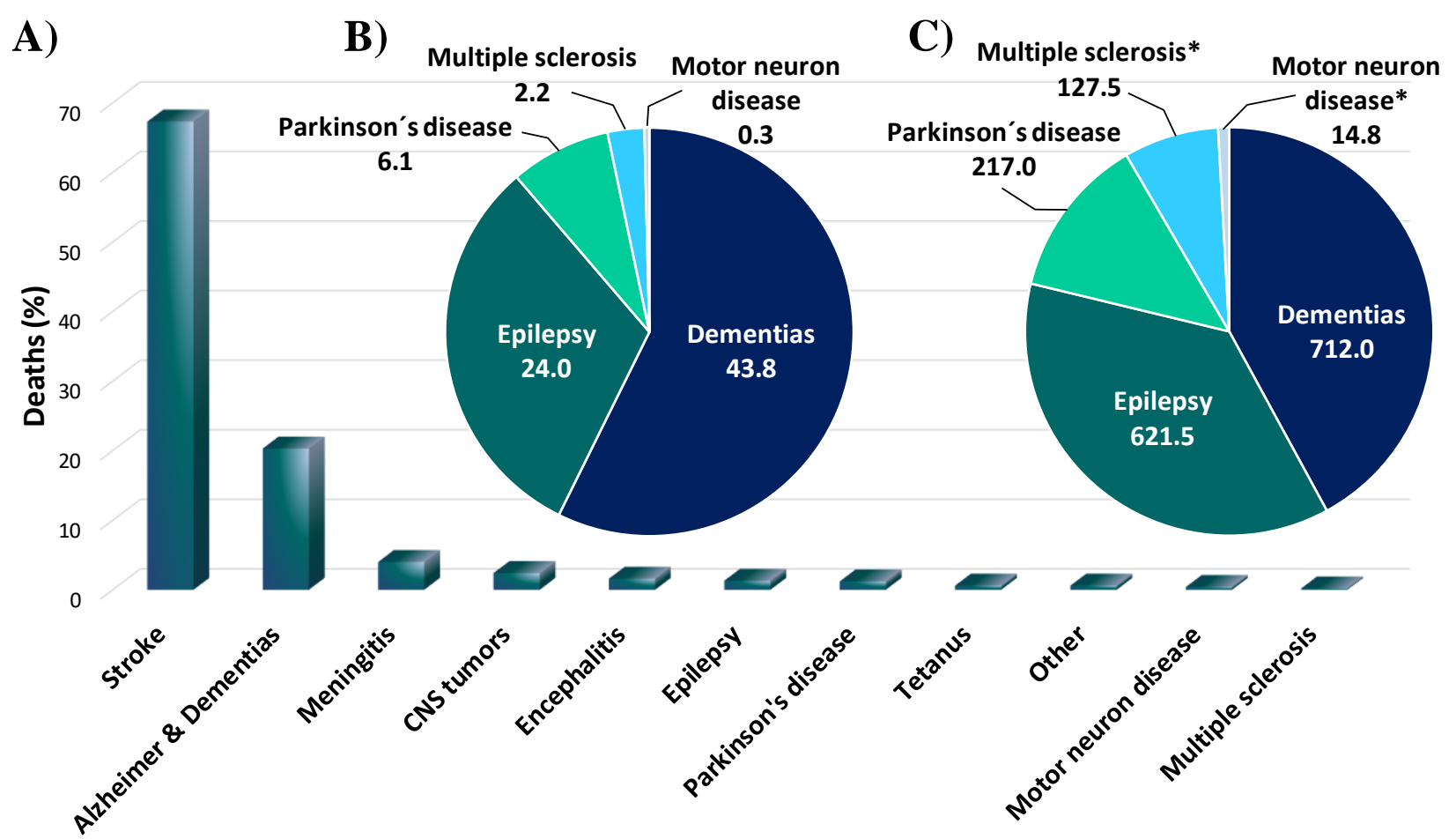

Figure 1. Most common neurological and ND diseases epidemiologic data. A) Deaths (\%) caused by the most common neurological disorders to the overall burden from neurological disorders in 2015. Data extracted from [4]. B) Number of individuals (millions) living with the disease worldwide in 2016. Data extracted from [6-10]. C) Age standardized prevalence of most common ND diseases per 100,000 global population in 2016. *Regions with high-income prevalence ratios: North America, western Europe and Australasia. Data extracted from [6-10].

Most ND diseases are multifactorial diseases driven by complex combinations of manifestations of longevity and genetic environmental factors [11]. Thus, aging, neuroinflammation, oxidative stress, mitochondrial dysfunction or metabolic disorders are among the contributors to the pathogenesis of ND diseases [1]. A common characteristic of these disorders is also their connection with alterations in the morphology and permeability of the blood-brain barrier (BBB) [12-14]. BBB dysfunction can drive inflammatory processes in the neural tissue, promote the infiltration of immune cells and immune mediators into the brain, and thus contribute to an increase in neurodegeneration [14]. As discussed below, the BBB does not only play an important role in the pathogenesis pf ND diseases, but also represents an important impediment to the efficient delivery of drugs to the CNS.

Gaining accurate insights into the pathogenesis of ND diseases is further complicated by their close relationship with aging. Brains of elderly people, who had not 
previously been diagnosed with a ND disease, frequently exhibit the presence of typical molecular and anatomical alterations characteristic of ND disorders, such neurofibrillary tangles, synaptic dystrophy, senile plaques, loss of neurons or reduced brain volume[1]. These features also vary greatly between individuals, and as such it is often not clear, which lesions or affected brain areas are a consequence of brain aging, and which are early manifestations of ND diseases. Many studies have reported the importance of efficient brain proteostasis for the maintenance of healthy brain tissues; with amyloid- $\beta$ A4 protein, stress-granule protein TIA1 or mutated Tau among the most studied examples [15-17]. Collectively, these studies suggest that loss of protein homeostasis in the brain could be closely related with the development of ND disorders. However, our knowledge of the functional consequences of such protein abnormalities is still preliminary and requires expansion.

Similarly, epidemiologic studies show that environmental factors account for at least $70 \%$ of variation in human lifespan. Specific behavioural patterns in lifestyle, such as drugs abuse or an unhealthy diet, can also strongly affect longevity and the development of ND diseases, and the relevant molecular pathways are still mostly unknown $[1,18]$. Genetic studies have shed light on some features of the processes underlying neurodegeneration. A large meta-analysis of an elderly cohort demonstrates that many of the single nucleotide polymorphisms related to longevity, as well as cognitive performance, are also negatively linked to developing $\mathrm{AD}$ and other cerebrovascular diseases, whereas healthy individuals do not exhibit this relation between longevity genes and neurological disease development [19]. Likewise, cell aging, gene expression and epigenetic DNA modifications have all been linked to the appearance of these pathologies. Importantly, brains from AD patients divert from the normally aged by exhibiting accelerated aging, ND stress and inflammation well before AD-specific biomarkers are detected [20]. Similarly, is has also been described that there is a relation between DNA methylation processes, accelerated aging, as well as AD and PD development [21-23].

\section{LIMITATIONS TO TREATING NEURODEGENERATIVE DISEASES}

\subsection{Blood-brain barrier restrictions}


The rate of entry of blood-borne molecules into the CNS is widely considered to be the single most important factor defining the success of pharmacological therapies targeting the brain [24]. As such achieving and maintaining a therapeutic threshold concentration of a given drug within the brain is one of the most important challenges facing CNS therapeutics. In this context, the BBB constitutes the main limitation of drug delivery into the brain, with the majority of drugs not being capable of crossing this physiological barrier [25].

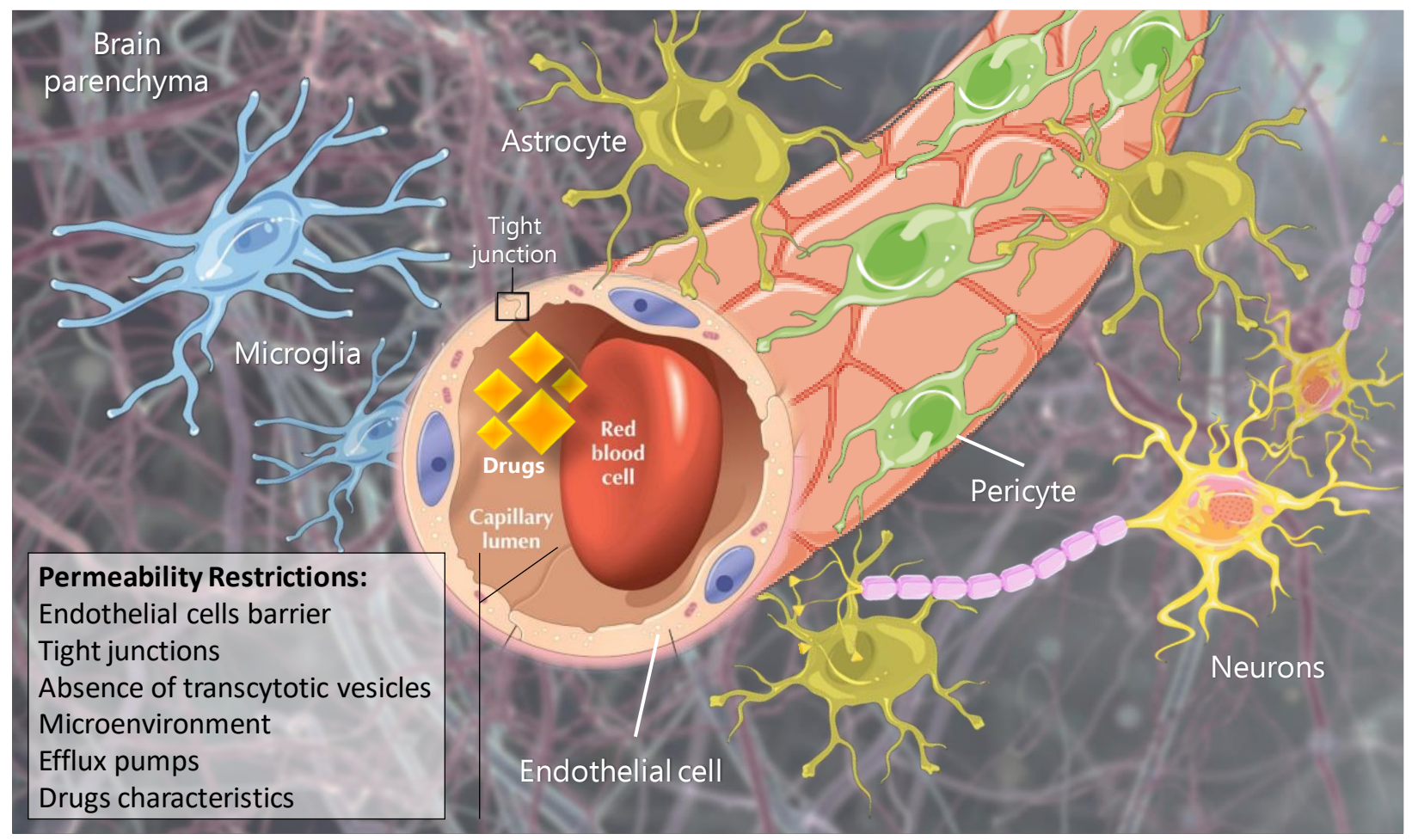

Figure 2. BBB neurovascular unit cells and most important permeability restrictions for CNS drugs.

$\mathrm{BBB}$ is a vascular barrier, but its features are defined by close, multifunctional interactions between vascular endothelial cells, astrocytes, pericytes, microglia and neurons, a cellular network commonly referred to as the neurovascular unit (NVU) [26]. Endothelial cells of the NVU form the main physical barrier restricting penetration of a wide variety of blood-borne molecules and cells. The restrictive nature of NVU endothelial cells is mainly due to tight junctions connecting individual endothelial cells, the paucity of transcellular transport, especially for hydrophilic drugs, as well as the efficient elimination of small molecules by efflux pumps [27]. NVU tight junctions are composed of an intricate complexes of paracellular, transmembrane proteins (e.g. occludins and claudinss) and their cytoplasmic regulators and cytoskeletal anchors [28]. In turn, lipophilic molecules may permeate the BBB through cellular membranes by 
simple diffusion. However, highly efficient efflux pumps often limit their accumulation in the brain. Likewise, the microenvironment of NVU cells regulates many of the barrier features of the vascular endothelial cells and vice versa [29].

To ensure the high metabolic demand of the CNS and its communication with the periphery the $\mathrm{BBB}$ displays a sophisticated system of selective, active transport mechanisms [28], the understanding of which is vital in designing successful CNS penetrating treatments. Indeed, several transport routes have been defined, by which solute molecules move across the BBB $[24,28]$. Entry routes of substances into the brain can be divided into paracellular (i.e. through the endothelial junctions) (Fig. 3a) and transcellular (i.e. through the endothelial cells by diffusion, channels or transcytotic vesicles). Small lipid molecules cross by transcellular diffusion pathway (Fig. 3b There are also specific transporters and channels, for essential molecules such as amino acids or glucose (Fig. 3c). Unwanted entry of molecules is restricted by powerful ATPconsuming efflux pumps, which have evolved to clear toxic molecules or pathogens from the brain parenchyma. These molecules of the ATP-binding cassette (ABC) transporter family, are also responsible for expelling most therapeutic drugs from the brain (Fig. 3d) Receptor-mediated transcytosis comprises active, energy dependent transport systems that rely on specific recognition of molecules to be transported (Fig. 3e). A wide variety of transmembrane receptors linked to clathrin-dependent endocytosis take up ligands such as transferrin, insulin and other proteins and petides vital for brain homestasis. Many of these receptors have been extensively studied and targeted for exogenous drugs transport to the brain. Adsorptive-mediated transcytosis is also an active transport requiring energy but not relying a specific recognition between the ligand and the carrier (Fig. 3f). Instead electrostatic interactions between the negatively charged surface of plasma membrane and a positively charged substance is the main driver of binding of molecules such as proteoglycans or albumin. Transport through the endothelial cell then occurs by vesiculation of the cargo and transcytosis. Adsorptive-mediated transcytosis has a higher capacity but lower affinity than receptor-mediated transcytosis and is mostly restricted to cationic molecules. Finally, the last transport route across the BBB is the cell-mediated transcytosis, also known as "Trojan horse" mechanism (Fig. 3g). Here the brain entry of some pathogens, such HIV, relies on the BBB transmigration of immune cells, such as macrophages or monocytes. All of these mechanisms have also been considered to be exploited as a feasible option for drug administration. 
Collectively, these molecular features of the BBB define important requirements for CNS efficient drugs transport, which therefore rely on integrity of the BBB, physicochemical properties of drugs (lipophilicity, molecular mass and charge, ABC recognition), their degree of receptor binding, metabolism, degradation and clearance, as well as cerebral perfusion. Broadly speaking, optimal drug characteristics for a drug crossing the $\mathrm{BBB}$ are high lipophilicity, small molecular weight and size, and low hydrogen-bonding potential [25].

a) Paracellular pathway

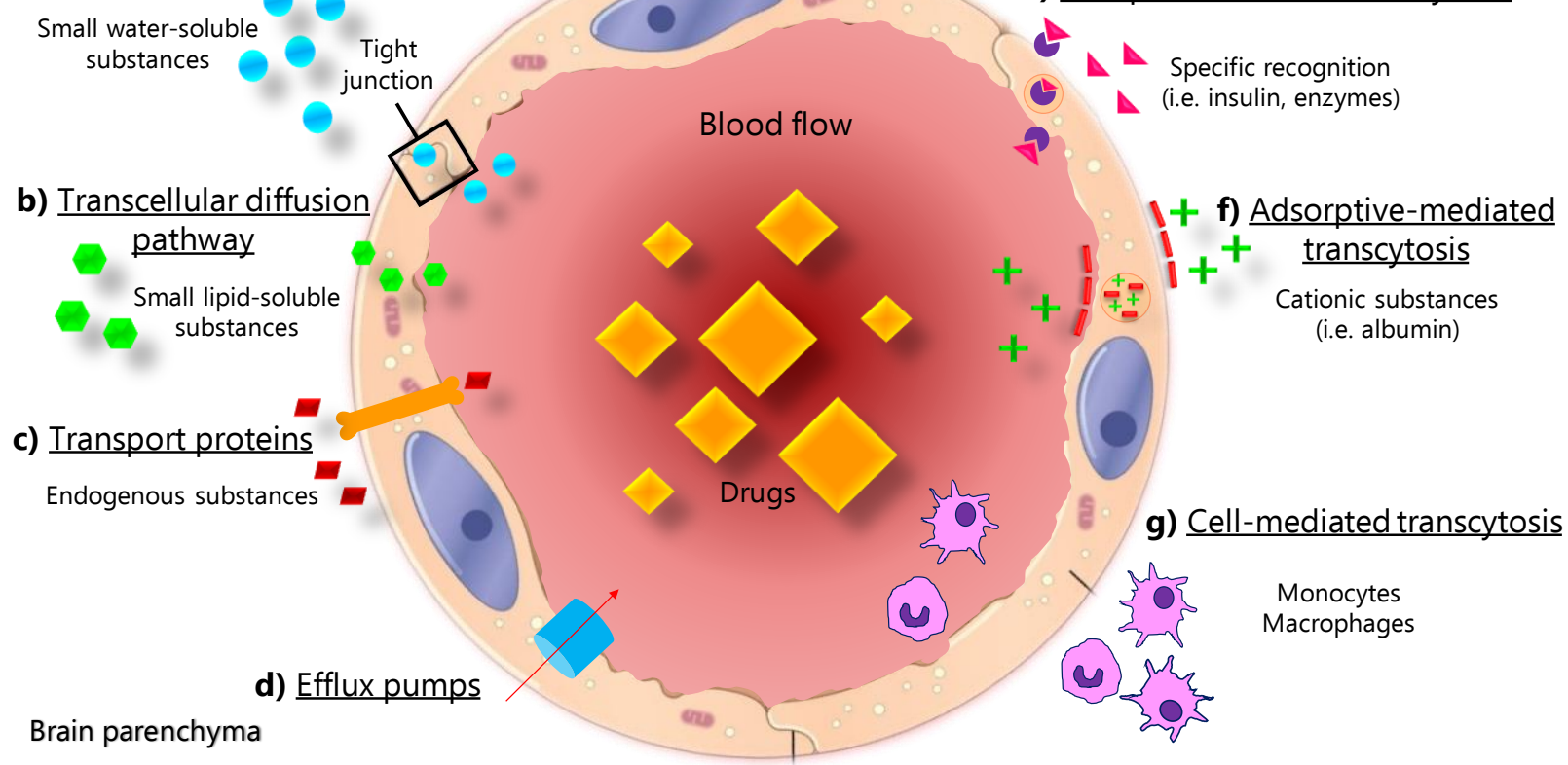

Figure 3. Mechanism of transport for endogenous and exogenous molecules across the BBB.

\subsection{Unclear etiology and late diagnose.}

Overall, neurodegeneration is complex and involves many molecular pathways, the pathological correlation of which is often hard to demonstrate. Although rare occurrences of ND diseases can be linked to defined genetic alterations, ND diseases are mostly of unknown origin.

Importantly, it is now clear that the pathogenesis of ND diseases is multifactorial and AD is a clear example. Familial, early-onset AD is linked to a genetic autosomaldominant pattern and affects around $5 \%$ of patients. By contrast, late-onset AD, a sporadic form of disease with unclear etiology, affects over $95 \%$ of patients. Much modelling of AD pathogenesis has focused on the amyloid cascade and Tau hyperphosphorylation [30]. Additional theories have emerged that develop a better understanding of disease 
pathogenesis. They show additional contributions of lipid and cholesterol dyshomeostasis, the immune system, mitochondrial dysfunction, deregulation of protein degradation pathway, as well as lack of intrinsic support of neurotrophic factors. Further co-morbidity factors are pre-existing medical conditions such as diabetes, hypertension, and cerebrovascular diseases, as well as environmental exposure to harmful substances, such virus or metal compounds [31]. Importantly, environmental factors have not only been related to $\mathrm{AD}$, but also to other ND diseases with an unclear origin such $\mathrm{PD}$, or amyotrophic lateral sclerosis [32]. Taken together, a lack of comprehensive knowledge of molecular pathways at the origin and during the development of ND diseases is closely related to therapy failure.

Another huge problem determining the success of neurodegeneration therapies is a generally late clinical treatment of these patients. This delay is mainly due to ate diagnosis which in most cases only occurs when the symptoms of neurological defects appear. Furthermore, such symptoms are common to several ND diseases or not specific enough, making a differential diagnosis often impossible [33]. Indeed, specific molecular alterations linked to differential diagnoses, such as amyloid plaques, are often only reliably detected in postmortem brain tissues[34]. In addition, at the currently relatively late stage of diagnosis, reversal of the neurological damage is generally impossible [34]. Thus, an early detection of the onset of neurodegeneration is crucial to provide chances for a therapeutic intervention that prevents further progression of the disorder. In this regard, current effective non-invasive diagnostic method, such novel neuroimaging techniques (i.e. positron emission tomography) or new genetic biomarkers detection (i.e. miRNAs), are among promising recent advances for early diagnosis and monitoring of these types of pathologies [33].

\subsection{Shortcomings of animal models}

A large number of animal models reproduce different features of most common ND diseases [35]. However, two important problems with available animal models limit the successful translation of pre-clinical findings to the clinic, and explain current deficits in our understanding of neurodegenerative pathogeneses. Firstly, important demographic characteristics and comorbidities of human patients (such as age, gender or concomitant diseases, such diabetes or hypertension) cannot generally be modelled in animals. Secondly, these models are not able to reproduce all the symptoms and characteristic 
molecular alterations of the disease. Typically, they are limited to induce pathology from a single point, putting considerable bias on the results obtained [36]. The development of more complete experimental animal models will undoubtedly be slow since it relies on a better insight into human pathogenesis. Thus for now, testing novel therapeutic approaches in as many relevant and varied models as possible must be considered the best approach to obtain more detailed, complete and extrapolatable information from animal models.

\section{POLYMERIC NANOPARTICLES AS CNS THERAPEUTIC TOOL}

In recent decades, advances in nanomedicine have resulted in the design of several controlled drug delivery systems. These systems provide protection to the drug, and increase the amount of the encapsulated compound at the target organ, which allows a reduction of the therapeutic dose, improves the inherent drug effectiveness, and reduce side effects [37].

Among the most used and studied controlled drug delivery systems are polymeric nanoparticles (PNPs) [38]. PNPs are characterized by an average size between 10 to 100 $\mathrm{nm}$, and negative/positive surface charge, depending on the polymeric matrix, and high drug loading capacity. Their constituent matrices can be of natural (e.g. gelatin or

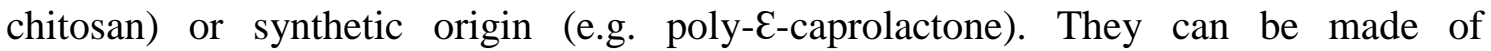
biodegradable polymers (e.g. poly(lactic-co-glycolic acid (PLGA) or cyanoacrylate) or non-biodegradable polymers (e.g. polyurethane) [39]. Most of the polymers used are approved by the Food and Drug Administration (FDA) and European Medicines Agency (EMA) and have been widely used in biomedicine applications because of their biodegradability, easy elimination by physiological mechanisms, biocompatibility and non-toxicity [40].

Manufacturing methods for PNPs differ, with polymers either created during nanoparticle synthesis, or by assembly of preformed polymers. The structure of PNPs also conditions their activity and transport across various physiological barriers. PNPs can be formulated as nanocapsules or nanospheres, leaving the drug encapsulated or entrapped in the polymer matrix, respectively [41]. In addition, non-ionic surfactants are widely used to formulate surface modified PNPs, since it helps to reduce interactions with phagocytic systems, such as through opsonization. Drug incorporation is generally 
achieved by one of two methods: it can be encapsulated inside the polymeric matrix, either during the preparation of PNPs with preformed polymers or during the polymerization step, or it can be added to the PNPs surface after the polymerization reaction [40]. A wide variety of methods to fabricate PNPs allow the encapsulation of drugs with different chemical nature and importantly, also address one of the main problems with many drugs, namely their low in vivo bioavailability caused by poor water solubility [42]. Thus, these types of vehicles significantly improve the biodistribution of the drug loaded and promote its sustained release. This greatly assists in controlling their dosage and kinetics, and consequently in enhancing their effectivity and reducing side effects $[43,44]$.

PNPs are able to promote the delivery of small molecules, peptides, proteins and nucleic acids to the brain. Surface modification of PNPs with molecules specifically providing brain targeting is another advantage of these nanosystems for CNS applications (Figure 4) [45]. Table 1 shows the most common ligands used to enhance specific targeting of polymeric-based NPs to the brain [46]. However, many nanosystems also enhance drug concentrations in the brain in the absence of active targeting, due to surface modifications, allowing passive diffusion of the loaded drug from the bloodstream to the brain parenchyma $[47,48]$.

The specific mechanisms, by which PNPs cross the BBB, are still under investigation and may differ between nanosystems used. Some investigators hypothesize that carrier mediated transport, receptor-mediated endocytosis or absorptive-mediated transcytosis are involved [49]. Irrespective of the actual mechanism, it is clear that the physicochemical properties of NPs define their ability to enhance drug accumulation in the brain. For instance, local, toxic effects of NPs on the tight junctions of BBB endothelial cells allows greater drug penetration through the BBB, in its free or incorporated form [50,51]. Likewise, it has also been shown that small NPs with average size of less than $50 \mathrm{~nm}$ allows their transport through brain endothelial cells by endocytosis [50]. 


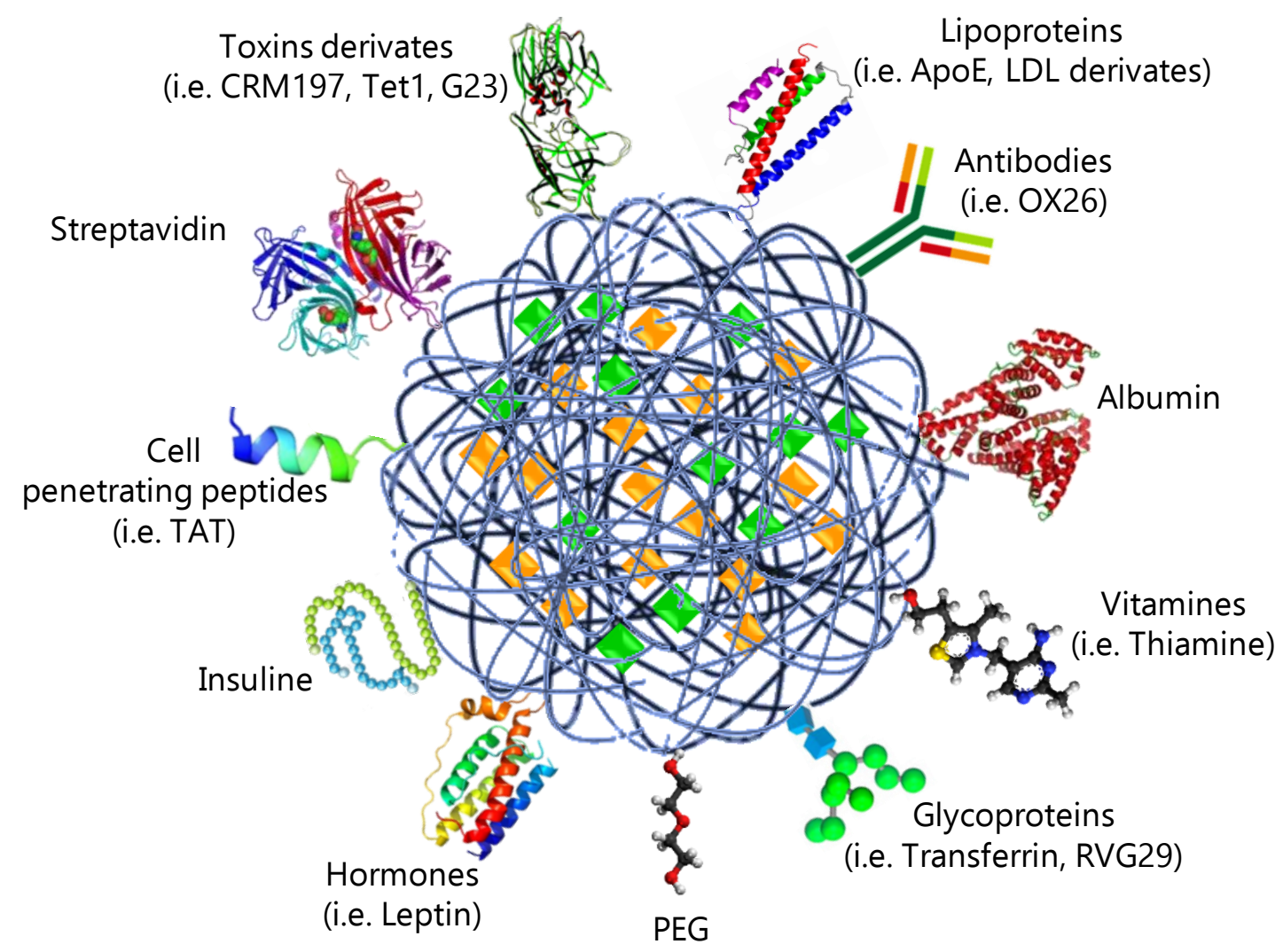

Figure 4. Scheme of most common surface modifications of PNPs for brain targeting. 
Table 1. Most common ligands used to coat polymeric nanoparticles for brain targeting and enhanced BBB penetration.

\begin{tabular}{|c|c|c|c|c|}
\hline Ligand & Type & Transport route & Specific Targeting Structure & References \\
\hline Transferrin & Iron-binding glycoprotein & Receptor-mediated transcytosis & Transferrin receptor & \\
\hline Biotin-Streptavidin & Proteins complex & Protein transporters & - & \\
\hline OX26 & Monoclonal antibody & Receptor-mediated transcytosis & Transferrin receptor & \\
\hline Melanotransferrin (p97) & Iron-binding protein & Receptor-mediated transcytosis & Transferrin receptor & \\
\hline Insulin & Endogenous protein & Receptor-mediated transcytosis & Insulin receptor & \\
\hline Albumin & Endogenous protein & Adsorptive-mediated transcytosis & - & \\
\hline LDL & Proteins & Receptor-mediated transcytosis & Endothelial LDL-receptor & \\
\hline ApoE & Apolipoprotein & Receptor-mediated transcytosis & Endothelial LDL-receptor & \\
\hline KPI-based peptides & Angiopeps & Receptor-mediated transcytosis & Endothelial LDL-receptor & \\
\hline Leptin & Hormone & Receptor-mediated transcytosis & Specific receptor ObR & \\
\hline Thiamine & Vitamin & Protein transporters & - & {$[46,49,52,53]$} \\
\hline Glutathione & Natural anti-oxidant & Receptor-mediated transcytosis & Glutathione receptor & \\
\hline Synthetic Opioid Peptides & Peptides & Protein transporters & - & \\
\hline $\begin{array}{l}\text { Rabies Virus Glycoprotein } \\
\text { (RVG) }\end{array}$ & Peptide & Receptor-mediated transcytosis & $N$-acetylcholine receptor & \\
\hline Tet1 and G23 & Tetanus toxin derivate peptides & Receptor-mediated transcytosis & GT1b receptor and ganglioside GM1 & \\
\hline CRM197 & $\begin{array}{l}\text { Non-toxic analog of the diphteria } \\
\text { toxin }\end{array}$ & Receptor-mediated transcytosis & HB-EGF receptor & \\
\hline TAT peptide & Cell penetrating peptides & Adsorptive-mediated transcytosis & - & \\
\hline PEG & Polymer & Paracellular pathway & - & \\
\hline
\end{tabular}




\section{CURRENT POLYMERIC NANOPARTICLES FOR THE TREATMENT OF NEURODEGENERATIVE DISORDERS}

\subsection{Polymeric nanoparticles for the treatment of Alzheimer's disease}

$\mathrm{AD}$ is characterized by a neuronal death, cognitive decline, memory loss and, ultimately, by an breakdown of basic functions, such as walking or swallowing resulting in the death of the patient [54]. It is the most common form of dementia worldwide representing $60-80 \%$ of all reported dementias [54]. According to World Alzheimer Report 2016, there are currently 47 million people with AD around the world, with predictions of 131 million by the year 2050 [55]. This increase will be accompanied by a large economic burden, estimated to reach one trillion dollars and may lead to financial shortfalls in both public and private health systems [55].

The etiological origins of AD are still largely unknown. Its incidence is associated with aging. Two main molecular pathways have been mechanistically linked and studied in depth, namely the appearance of senile plaques and neurofibrillary tangles, caused by the accumulation of amyloid- $\beta$ (A $\beta$ ) peptide, and of hyperphosphorylated tau protein, respectively [30]. To date there are four pharmacotherapy options for AD approved by the FDA and EMA: the acetylcholinesterase inhibitors donepezil, galantamine and rivastigmine, for mild to moderate disease, as well as the NMDA receptor antagonist memantine, for moderate and severe stages. However, none of them stops the progression of the disease [54]. Thus, there is an urgent need to find new therapeutic modalities to combat this pathology, and the versatility of nanotechnology opens novel, promising alternatives for pharmaceuticals to be delivered to the brain (Table 2).

Many hypotheses have emerged to explain $\mathrm{AD}$ pathogenesis. The negative effect of oxidative stress is one of them [56,57]. Indeed, recent advances are focusing on the use of natural antioxidants in combination with nanotechnology, to assist in targeting but also improve their low bioavailability and stability, and reduce side effects. In a recent study, Cano et al. developed a nanovehicle of epigallocatechin-3-gallate (EGCG), the main polyphenol of the tea plant, which has aroused great interest for the treatment of a variety of diseases [51]. The PNP system in this study consists of a polymeric matrix of PEGylated PLGA, formulated in an antioxidant environment provided by coincorporation of ascorbic acid (AA). Both nanoencapsulation and AA preserve the chemical nature of EGCG and protect it from in vivo clearance, thus resulting in an 
increase its bioavailability and efficacy. Results show that this nanosystem is able to cross the BBB. Furthermore, in a transgenic mice model of $\mathrm{AD}$, it significantly reduces the astrogliosis process and $\mathrm{A} \beta$ plaque burden, and enhances the synapsis expression, spatial learning and memory processes, overall demonstrating pharmacological effectiveness. In a comparable study, Sun et al. encapsulated quercetin (QT), a flavonoid found in many fruits and vegetables, into PLGA matrix and investigated its effects on inhibition and disassembling of A $\beta 42$ fibrils [58]. Such NPs enhance the viability of neuronal cells, ameliorate cognition and memory impairments without any signs of adverse effect in different organs of treated mice.

Keeping with delivering natural products, and going one step further to enhance drug penetration through the $\mathrm{BBB}$, Ahlschwede et al. recently developed a curcumin loaded PLGA nanocarrier with a multi-functionalized coating, composed by chitosan, antibodies and penetrating peptide K16ApoE [59]. K16ApoE-targeted NPs migrate efficiently through the $\mathrm{BBB}$, demonstrating active targeting and greater uptake into the brain, and provides specific MRI contrast to detect $A \beta$ plaques. Curcumin has also been investigated for potential biomedical therapy in addition to other compounds, such as selenium, which might play different preventive roles in the progression of $\mathrm{AD}$ [60] . In this context, Huo et al. developed a combined carrier of curcumin/selenium, which aimed to inhibit $A \beta$ aggregation [61]. This nanocarrier binds $A \beta$ oligomers in a selective manner, opening a new avenue of targeted pharmacotherapy.

Other chemical elements have been incorporated into AD-targeting NPs. Of note are efforts to increase Zinc levels in the brain. Vilella et al developed a zinc loaded polymeric nanocarrier with a BBB penetration peptide coating for more efficient targeting [62]. This study shows that zinc-loaded PLGA NPs are able to reduce significantly the level of neuroinflammatory cytokines levels and $A \beta$ plaque burden without any negative behavioural effects in transgenic $\mathrm{AD}$ mice.

Neuroinflammation plays a role in the pathogenesis of AD. Microglia, macrophage-like resident immune cells in the brain, are activated by the presence of toxic species like $A \beta$ peptide and TAU neurofibrillary tangles. This activation can lead to the production of many neurotoxic molecules, such as glutamate, reactive oxygen species or inflammatory cytokines, which differentially induce neurotoxicity [63]. Especially in advanced disease stages, microglia activation also contributes to molecular neurotoxicity 
in AD and neuroinflammation has been therapeutically targeted in AD [64]. SánchezLópez et al. used a PEGylated polymeric nanosystem loaded with dexibuprofen (DXI, the active enantiomer of ibuprofen) [65]. When applied in a well-established mice model of $\mathrm{AD}, \mathrm{DXI}$ in the nanocarrier shows greater efficacy than in its free form, by reducing microglia activation and $\mathrm{A} \beta$ plaques area, as well as memory impairment and cognitive decline. However, other evidence shows a neuroprotective role of microglia in the development of $\mathrm{AD}$, suggesting that microglia do not only promote neuroinflammation during $\mathrm{AD}[66]$. For instance, during $\mathrm{A} \beta$ plaque depositions microglia encapsulate these amyloid deposits, thus creating what has been called a "microglia barrier"[67]. This barrier modulates and compacts the $\mathrm{A} \beta$ plaque surface area, and insulates it from adjacent axons, thus reducing neurotoxicity. Moreover, recent genetic studies show that an increased risk of late onset $\mathrm{AD}$ development is partly related to deficient microglia polarization toward $A \beta$ plaques deposits [67,68]. Similarly, an inverse correlation between plasma neurofilament light levels as marker of axonal degeneration, and neuroinflammation in cortical areas was recently described [69]. Thus microglial activation could have an initial protective role in axons and its targeting must be well controlled.

Peptides are used in NPs not only for improved targeting of the BBB but are also delivered as direct therapeutic molecules. In a first study carried out in 2014, Zhang and colleges explored the potential use of the H102 peptide, a $\beta$-sheet breaker peptide, encapsulated in polymeric NPs for the treatment of AD [70]. Two different nanocarriers with either TGN and QHS surface coating were employed to deliver the peptide. Results show an improved brain penetration of $\mathrm{H} 102$ with both nanocarriers and an increase in the spatial learning and memory processes of the AD mice. Three years later, the same group published a second study with the two surface coatings combined in the same nanovehicle, leading to even greater delivery of $\mathrm{H} 102$ peptide [71]. Overall, this results in even better ability of the nanosystem to decrease $A \beta$ plaques and tau protein phosphorylation, to protect synapses, increase $A \beta$-degrading enzymes and improve the spatial learning and memory of transgenic AD mice. These studies illustrate the particular importance of coating techniques to improve the therapeutic success of nanomedicine in AD. The delivery of endogenous proteins and peptides as therapeutic modality also is arousing much interest in nanomedical applications for AD. Thus, Seong et al. formulated vitamin D-binding protein (DBP) PLGA NPs [72]. DBP could attenuate A $\beta$ aggregation 
and accumulation, but it is rapidly metabolized after its in vivo administration. Thus results show that DBP-PLGA NPs significantly inhibits $A \beta$ aggregation in an in vitro model and in vivo are able to attenuate significantly neuroinflammation, $\mathrm{A} \beta$ accumulation, neuronal loss and cognitive dysfunction.

Similarly, proteins and in particular monoclonal antibodies (MAbs) have been used in NPs, and these have often been dubbed 'immuno-NPs'. However, most of these are simply NPs that carry surface modifying MAbs to target BBB receptors and promote transport to the CNS (see Table 1). However, NPs can also be used for active and passive immunotherapy. Our understanding of CNS immunity has evolved dramatically over the past century. The brain, initially perceived as an immune privileged site without communication with the peripheral immune system and relying solely on resident microglia, has been shown over the last 30 years to be intimately integrated with immune responses regulated by the periphery. This has opened the prospect of active immune therapy for ND diseases, involving immunisation to empower the peripheral immune system to combat $\mathrm{AD}$ and dementia [73]. Whilst these approaches have shown some promise, advances have been fraught by inconsistencies on the level of the immune response achieved [74-76]. Importantly, in the context of this review, nanotechnology has not yet been exploited to support therapeutic strategies of active immunotherapy. In contrast, nanotechnology has undertaken some steps towards passive immunotherapy, which consist of the generation of MAbs targeting pathogenic molecules, their humanisation in the laboratory and subsequent administration in animal models and patients [77,78]. Importantly, as discussed above, nanotechnology can potentially assist the delivery of these large, normally impenetrable synthetic proteins across the BBB.

Carradori et al. developed a novel surface modified PNP with a monoclonal antibody targeting A $\beta 1-42$ [79]. This study aimed at reducing brain $A \beta$ through binding of blood-circulating $A \beta$ peptides and their elimination by classical NPs elimination pathways. Indeed, AD-like animal treated with this nanovehicle show reduced levels of $A \beta$ soluble peptide and its oligomer in the brain, a concomitant increase of plasma $A \beta$, and strikingly a complete memory loss reversion. In a more preliminary study, Jaruszewski and colleagues show that chitosan coated PLGA NPs conjugated with a novel anti-amyloid antibody efficiently bind fibrillar A $\beta 40$ and penetrate MDCK cell monolayers, used as a model for the BBB [80]. Undoubtedly more studies with MAbcoated NPs will emerge in the near future. 
Lastly, PNPs are also successfully used to deliver genetic modifiers. In this context, a recent study by Liu et al. shows efficient delivery of a therapeutic gene by multifunctional NPs in an in vivo model of AD [81]. These NPs were composed by: (i) rabies virus glycoprotein 29 (RVG29), a brain-targeting peptide which has been shown to bind the specific n-acetylcholine receptors expressed in $\mathrm{BBB}$ and brain parenchyma cells; (ii) Plasmid DNA encoding BACE1-AS shRNA, to be delivered into the brain to perform a down-regulation of BACE1, closely related with $\mathrm{A} \beta$ plaque formation; and (iii) D-peptide, an all-D amino-acid inhibitor which has been shown to disrupt Tau-fibril formation. The combination of these cargos reduces memory loss and neurofibrillary tangles in NPs-treated transgenic mice, with a clear down-regulation of the key enzyme in $\mathrm{A} \beta$ plaque formation.

\subsection{Polymeric nanoparticles for the treatment of epilepsy}

Epilepsy is a neurological disorder characterized by an imbalance in the electrical activity of neurons which gives rise to recurrent seizures. Convulsions intensity can range from mild attention loss to severe seizures, the latter commonly accompanied by a loss of consciousness. Molecular mechanisms associated with development of epileptic symptoms involve an imbalance of glutamate levels and concomitant excitotoxicity [82]. Epilepsy is also associated with a number of neurodegenerative alterations in the brain regions where repeated seizures commonly occurs [83]. It is estimated that $1 \%$ of the general population suffers from epilepsy, affecting approximately 70 million people of all ages worldwide [84]. Epilepsy disorders were ranked as the second most burdensome neurologic disorder in terms of DALYs by the WHO's 2010 Global Burden of Disease study [85].

Even though epilepsy is one of the neurological diseases with a relatively large number of available treatments, many patients present resistances to conventional antiepileptic drugs (AEDs). In fact, one third of patients show a therapeutic failure without any significant benefit from currently available drugs. Moreover, AEDs are drugs with a narrow therapeutic range and significant adverse effects, substantially complicating their use in disease management [86]. Because of that, many efforts are 
underway to find new drugs for those forms of epilepsy, which do not respond to the current treatments, and to improve the disadvantages of conventional drugs [87].

Nanotechnology is considered one of the best strategies to improve pharmacological properties of conventional AEDs and reduce their marked side effects (Table 2). One promising example is the study performed by Zybina et al., in which carbamazepine (CBZ), a first generation AEDs, was incorporated into a polymeric nanovehicle for the treatment of refractory epilepsy [88]. This study also evaluates the negative effect of P-glycoprotein (Pgp), one of the main ABC transporters limiting drug entry into the brain parenchyma. Importantly, the anticonvulsive effect of CBZ is 30-fold higher when encapsulated into PLGA-NPs, and the inhibition of Pgp does not affect nanocarrier efficacy. In this context, Fang and colleges show that phenytoin (PHT) resistance in Pgp overexpressing rats can be overcome by loading it into poly(butylcyanoacrylate) NPs [89]. PHT-PBCA-NPs increase the ratio of the area under curve (AUC) of the PHT concentrations in the brain/plasma in comparison with free drug treatment and exhibit a significant anticonvulsant activity in the PHT-resistant rats.

Another first generation AED widely used in the conventional pharmacotherapy is oxcarbazepine (OXC). Recently, Musumeci and colleges carried out a study with free or PNP-loaded OXC as a novel approach for epileptic seizures [90]. This research reveals that intranasal administrations of OXC-loaded PNPs controls seizures in a rat model of epilepsy and reduces the number of administrations required for maximal benefit when compared to the free drug. Moreover, there is also increased neuroprotection by OXC when loaded in PLGA NPs. These results reveal a novel non-invasive nose to brain delivery system of a common AED as a promising alternative for the treatment of epilepsy disorders. Overall, these studies give a second lease to conventional AEDs, by exploiting their demonstrated benefit and extending their narrow therapeutic range.

In addition, just as for $\mathrm{AD}$, drugs with novel mechanism are being studied in combination with incorporation into nanovehicles. Many investigators have tested the use of natural products for the treatment of epileptic episodes. Thus, Hashemian et al. recently developed a curcumin-loaded chitosan-alginate-STPP nanocarrier, which is able to reduce neuroinflammation and ameliorate memory deficits in an in vivo model of epilepsy [91]. In a follow-up study, this group shows that neuroprotection is due to upregulation of klotho a life extension factor, and erythropoietin (EPO) [92]. 
Another natural product of interest to treat epilepsy disorders is EGCG. Although the mechanism of action has yet to be elucidated on a molecular level, several authors have reported effectiveness of this molecule in the reduction of the number of seizure episodes and their intensity, as well as the pathological alterations derived from them, such neuronal death of the affected areas [93-95]. As discussed above nanotechnology is being applied to improve pharmacokinetic characteristics of EGCG and its delivery to the brain to take full advantage of its therapeutic potential. Thus, Cano and colleagues report the encapsulation of EGCG in PLGA NPs coated with PEG and their efficacy in a kainic acid (KA)-induced mouse model of temporal lobe epilepsy [96]. This nanocarrier formulation is non-toxic and reduces the number of seizures and their intensity more efficiently than the free drug. Mechanistically, EGCG PLGA-PEG NPs decreases neuronal death and neuroinflammation, confirming the contribution of the nanovehicle formulation to the significant improvement of EGCG's therapeutic effectiveness. Similarly, piperine, a natural alkaloid extracted from black pepper, has been mooted as a suitable candidate for epilepsy disorders. This compound possesses strong anticonvulsant activity, but its low water solubility limits its biomedical application. Anissian et al. use piperine-loaded PNPs, which, in the pentylentetrazol (PTZ)-kindling model of epilepsy, are able to reduce astrocytes activation and neuronal loss to greater extent than the free compound [97].

Lastly, biological molecules are also being investigated as novel therapies for epilepsy disorders. Thyrotropin releasing hormone (TRH), which generally controls thyroid homeostasis and prolactin functioning, displays significant antiepileptic activity in several animal models, suggesting therapeutic potential of TRH and its analogues in the treatment of this disease [98]. However, short half-lives and poor bioavailabilities limit their clinical use. In a recent study, Kaur and collaborators incorporated synthetic analogues of TRH into PLGA-chitosan NPs [99]. This encapsulation potentiates their anti-epileptic activity, compared to their respective free molecules, presumably due to a positive effect of the chitosan modification and polymeric shell on body retention, nasal cavity internalization, and brain penetration

\subsection{Polymeric nanoparticles for the treatment of Parkinson's disease}

PD is characterized by a progressive loss of dopaminergic neurons, mainly present in the substantia nigra, accompanied by a degeneration of dopaminergic terminals in the 
striatum, thus leading to movement coordination impairments but also cognitive decline, depression or anxiety. It is the most common motor disorder and the second most prevalent neurodegenerative disease It is incurable, with an unknown etiology in most cases. A systematic analysis for the Global Burden of Disease Study 2016 pointed out that PD was the fastest growing in prevalence, disability, and deaths, affecting at $1 \%$ of the population above 60 years, which equals to $1-2$ over 60 s per 1000 at any given time $[8]$.

Available treatments are based on dopamine precursors, usually in the form of LDOPA. These drugs provide a symptomatic therapeutic approach, but do not stop the disease progression, and thus commonly fail to improve many motor and non-motor symptoms. Many PD patients require long-term treatment which offers clear benefits only to few, with many patients experiencing various adverse effects [100]. This highlights the need for novel treatments and again nanomedicine offers the possibility to render available drugs more specific. Gambaryan et al. investigated L-DOPA PLGA-based NPs for PD treatment [101]. A four-week treatment with either NP-L-DOPA or L-DOPA alone shows no effect of the drug alone in Wistar rats with 6-OHDA-induced PD. In contrast NP-L-DOPA enhanced coordination movements by a factor of two. This is linked to significantly longer half-life, better bioavailability and efficacy of NP-L-DOPA. Importantly, in this study the drug was efficiently delivered to the brain by intranasal administration.

In the long term clinical effectiveness of L-DOPA decreases in the treatments of PD, mainly because of the on-off effects caused by the fluctuations in L-DOPA concentration in the brain. Thus alternative drugs have been investigated, many in the form of nanovehicles for the treatment of PD (Table 2) [102]. Because nicotine offers neuroprotection against 1-methyl-4-phenyl-1,2,3,6-tetrahydropyridine-induced parkinsonism, Tiwari and colleagues explored the use of nicotine-loaded PLGA NPs [103]. Nanocarrier treatment increases the mRNA expression of neuronal cell adhesion molecule and tyrosine hydroxylase (TH), among others, and improves the number of fibre outgrowths and resilience of $\mathrm{TH}$ immunoreactive neurons. Likewise, the modulation of TH immunoreactivity, dopamine metabolites levels, microglial activation, expression of p53, iNOS, GSTA4-4, HO-1, MT-III and other markers of parkinsonism is more pronounced following treatment of parkinsonian mice with PLGA NP-encapsulated nicotine as compared to that with free drug. Taken together, this study demonstrates the 
beneficial effect of enhancing nicotine bioavailability in neuroprotection, and subsequent modulation of oxidative stress and apoptosis indicators. Another noteworthy study in this context is by Raj and collaborators, which describes the development and characterization of chitosan NPs of pramipexole (PM), a dopamine agonist used especially in combination with L-DOPA or IMAO-B to effectively counter PD progression [104]. In this study, nasal solutions of PM PNPs significantly improve the photoactometer score and motor deficit in behavioural tests compared to PM alone. Moreover, PM PNPs significantly increases dopamine level in the brain along with enhanced antioxidant status. Another excellent candidate for nanomedicine is selegiline, a well-known anti-Parkinson agent of the IMAO-B family, which normally exhibits poor oral bioavailability and safety. Sridhar et al. show that loaded in a chitosan nanocarrier it significantly improves locomotor activity, catalepsy and stride length of treated animals, in combination with increased catalase activity, dopamine and glutathione brain content [105].

Gene therapy has also gained much attention in the recent years for PD treatment [106]. $\alpha$-synuclein (SNCA), a pre-synaptic protein, which self-associates into toxic oligomers in PD, represents a novel promising therapeutic targets. Its downregulation can be achieved by using synthetic small interfering RNAs (siRNAs) [106]. In this context, Helmschrodt and colleges show that a polyethylenimine NP-based delivery system carrying siRNA against SNCA expression is effective in an in vivo model of PD [107]. A single injection of siRNA formulated in PNPs results in striatal mRNA and protein reduction of SNCA by 50 and $65 \%$, respectively. This occurs in the absence of any signs of neuroinflammation in the brain parenchyma and ependymocytes. Related to this, Gan et al. recently published a study which evaluates the association of RVG29 (the BBBtargeting ligand) and microRNA-124 (which has been shown to be involved in differentiation of neurons in neural progenitor cells as well as decrease levels of inflammatory cytokines) in PNPs as a novel genetic therapeutic approach for PD [108].

Interestingly, results showed that transfection of cells with these miR-PNPs increases the mRNA levels of pro-inflammatory cytokines and neuroprotective molecules. Going further, Saraiva et al. used loaded miR-124 to investigate its effectiveness in a 6-hydroxydopamine (6-OHDA) mice model of PD [109]. These NPs contained perfluoro-1,5-crown ether (PFCE), a compound that can be tracked by Fluorine (19F)-magnetic resonance imaging, and coated with protamine sulfate to complex miR124. Intracranial administration of miR-124 NPs increases migration of neuroblasts to the 
granule cell layer of the olfactory bulb, and of neurons into the lesioned striatum. Functionally, miR124 NPs treatment improves motor symptoms of PD mice.

\subsection{Polymeric nanoparticles for the treatment of Huntington's disease}

Huntington's disease (HD) is an uncommon, autosomal-dominant progressive neurodegenerative disease triggered by a mutation in the Huntingtin (HTT) gene. This disorder involves a distinct phenotype, including chorea and dystonia, cognitive decline, incoordination, and behavioural difficulties [110]. In HD the HTT gene displays an abnormal CAG repeat expansion, which produces increased poly-glutamine repeat sequences in the HTT protein. However, the function of this protein or its role in the onset and progression of the disease are currently unknown [111]. The pathogenesis of HD involves degeneration of the basal ganglia, especially the caudate and putamen. GABAergic medium-sized spiny neurons are most strongly affected [112].

Patients death usually occurs within 15 to 17 years following disease onset. Prevalence of HD prevalence shows great variation around the world, with more than tenfold differences between certain geographic areas [113]. In developed countries HD affects around 5-10 per 100,000 individuals. The main reason for higher prevalence rates of HD is thought to be earlier diagnosis due to better access to genetic tests and better clinical knowledge of HD pathogenesis. However, a recent increase in HD numbers might also be due to increased mutation rates [113].

Although the genetic mutation leading to HD was identified 20 years ago, there are still no effective therapies to cure, delay the onset or slow the progression of HD [114]. The only two approved drugs of HD-related symptoms involves the treatment of chorea. These are tetrabenazine, an inhibitor of the vesicular monoamine 2 transporter. and its deuterated version (SD-809), which shows equivalent efficacy but better tolerability in clinical trials [114]. However, these drugs do not cure the disease and cause serious adverse effects, such depression and suicidal attempts [115].

Trehalose is one of the most promising novel molecules for this disorder. It has been shown to inhibit insulin, $\alpha$-synuclein and $A \beta$ fibrillation, and alleviate polyglutamine-mediated pathology in HD mouse $[116,117]$. In the context of nanomedicine, Debnath et al. formulated iron oxide core/zwitter-ionic polymer shell NPs containing 
covalently linked trehalose and evaluated their effect in a transgenic mice model of HD [118] (Table 2). This nanocarrier formulation is up to 10,000 times more efficient than free trehalose in blocking aggregation of poly-glutamine-containing mutant HTT in neuronal cells. It also inhibits protein fibrillation in the extra-cellular space and also suppresses mutant HTT aggregates in HD transgenic mice brains. The same group also studied effectiveness of EGCG incorporated in PNPs in cells modelling HD [119]. Encapsulated EGCG is 10-100 times more efficient than soluble EGCG in disintegrating mature protein aggregates, inhibiting protein aggregation and lowering $\mathrm{A} \beta$ cytotoxicity. Moreover, PNP-EGCG protects neuronal cells from the toxicity of extracellular A $\beta$ or intracellular mutant HTT aggregates by preventing their aggregation.

Cholesterol levels are reduced in the brains of mouse models of HD and neuronal lack of this crucial membrane lipid may contribute to the disease. Blood borne free cholesterol does not cross BBB per se, but Valenza and colleagues show that cholesterolloaded into brain-targeted PNPs results in high brain loading of cholesterol [120]. Importantly, the repeated systemic delivery of the cholesterol nanosystem results in rescue of cognitive dysfunction, synaptic loss and partially improvement of global activity in transgenic HD mice.

Genetic therapy is also arousing much interest in the treatment of HD and the use of siRNAs to silence the mutant protein is one of the most promising novel therapeutic strategies. Thus, Godinho and collaborators developed self-assembling modified $\beta$-cyclodextrin NPs for the brain delivery of siRNA to silence toxic HTT [121]. In this study NP formulation is associated with an increase in stability of the siRNA in an artificial cerebrospinal fluid and a strong reduction of expression of the HTT gene in rat striatal cells and in human HD primary fibroblasts. In HD transgenic mice, these NPs result in sustained knockdown of HTT in the striatum and, following repeated brain injections, selective alleviation of motor deficits.

\subsection{Polymeric nanoparticles for the treatment of multiple sclerosis}

MS is the most common inflammatory neurological disease in young adults. It is a chronic, heterogeneous, disabling autoimmune disease characterized by demyelination, neuroinflammation, oligodendropathy and neuronal degeneration, which affects both gray and white matter [122]. The origin and precise etiology of MS is not clear. However, key to the pathogenesis of MS is an autoimmune response directed against 
oligodendrocytes and myelin. Demyelination leads to a primary neurodegeneration, an essential step in MS development. Subsequent secondary neuropathy manifests as abnormalities in the visual, cognitive and autonomic systems, and motor deficits. Metabolic disturbances involving oxidative stress, mitochondrial dysfunction and metal dysregulation have also been implicated in the pathogenesis of MS [122]. Atrophy of brain and spinal cord are mainly caused by a progressive degenerative process of white and grey matter, which gives rise to the common physiopathogenic manifestations of MS [123].

Prevalence has increased substantially in many regions since 1990. The last report of the Global Burden Disease of Multiple Sclerosis estimated that, in 2016, there were $2,221,188$ cases of multiple sclerosis globally, which corresponded to a $10.4 \%$ increase in the age-standardised prevalence since 1990 [9]. There were 18,932 deaths and $1,151,478$ DALYs due to multiple sclerosis in 2016 and the highest age-standardised MS prevalence values were detected in high-income in developed countries of North America (164.6), Western Europe (127.0), and Australasia (91.1) [9].

At present, there are no cures for MS, just palliative treatments. The therapeutic objective is based on reducing each symptom separately, thus preventing disability by promoting the maintenance and recovery of tissues. Thus, pharmacological treatment involves steroids, for the acute episodes or relapses, and immunomodulatory and immunosuppressive drugs, for the modification of the course of the disease, with molecules such fingolimod, natalizumab, mitoxantrone or teriflunomide used for relapsing-remitting MS [124]. However, there are many patients, who do not respond in predicted ways to these therapeutic options and who manifest a more rapid and aggressive disease progression. For these reasons, it is necessary to find new treatments and novel pharmaceutical modalities for MS patients (Table 2).

Tolerogenic therapies are based on inducing non-differentiated dendritic cells and then exposing them to the target antigen, which should lead to antigen-specific T-cell tolerance. Rapamycin inhibits the mTOR signalling pathway, which has been shown to induce tolerogenic dendritic cells in some in vitro models. This suggests that this compound is also capable of stimulating regulatory $\mathrm{T}$ cells, which can promote tissue damage when escaping tolerogenic control mechanisms, thus resulting in autoimmune disease, and suppressing disease when adoptively transferred in vivo [125]. This drug has 
been mooted by many investigators as a promising alternative for MS, and has been tested in conjunction with NPs. A recent study carried out by LaMothe et al. developed PNPs of rapamycin co-loaded with specific antigens (Ag) against $\mathrm{T}$ cells [126]. In vivo treatment with this nanosystem demonstrate that NP-treated mice do not develop experimental autoimmune encephalomyelitis (EAE), a widely used rodent model of MS. Moreover, these PNPs provide therapeutic protection in an adoptive transfer model of relapsing EAE. Similarly, Maldonado and colleagues designed rapamycin-loaded PNPs for the induction of Ag-specific immunological tolerance in EAE [127]. In this study authors demonstrate that only encapsulated rapamycin but not free induces immunological tolerance. Nanocarrier treatment causes inhibition of Ag-specific hypersensitivity reactions, CD4+ and CD8+ T-cell activation, and an increase of regulatory cells and B-cell tolerance resistant to several immunogenic challenges in EAE mice.

As polymeric nanocarriers with specific MS Ag as surface modifiers have shown promise in this field, other studies have focused on this aspect. On the one hand, Kuo et al. induced an Ag-specific tolerance in EAE mice with PLGA NPs conjugated with peptides of myelin proteolipid protein (PLP $139-151)$, ovalbumin $\left(\mathrm{OVA}_{323-339}\right)$, and I-E $\alpha$ (E052-68), all of them disease-relevant antigens [128]. This nanocarrier suppresses inflammatory signalling, resulting in significant reduction of co-stimulatory molecules (CD86, CD80, and CD40) and of T cell proliferation. On the other hand, Pearson and colleagues conjugated PLGA NPs with OVA $323-339$ and PLP139-151 or PLP $178-191$ to evaluate their effect on the in vitro activation and differentiation of naive activity of CD4 $4^{+}, \mathrm{CD} 25^{-}$ and Foxp3- T cells, as well as on clinical development of relapsing-remitting EAE in mice and reported that nanocarriers can modulate maximal levels of regulatory $\mathrm{T}$ cell induction [129].

MS and EAE are usually accompanied by progressive demyelination of neuronal axons. This not only removes the metabolic support of axons, but also prevents the saltatory electrical signal conduction along them, leading to ineffective neuronal signalling and irreversible neurodegeneration. A recent study by Pei and colleagues shows modulation of myelin-autoreactive $\mathrm{CD} 4^{+}$and $\mathrm{CD} 8^{+} \mathrm{T}$ cells by a tolerogenic PNPs co-carrying transforming growth factor (TGF- $\beta 1$ ) and multiple regulatory molecules, such anti-Fas and PD-L1-Fc [130]. In vivo treatment with these PNPs improves EAE clinical score, with a marked reduction in demyelination and neuroinflammation. Another 
noteworthy study by Rittchen and collaborators exploits findings of loaded-leukaemia inhibitory factor (LIF) as a pro-myelination factor [131]. Here the investigators evaluate the myelin repair processes following treatment with LIF NPs. In vitro, these NPs induce differentiation of precursor cells into mature oligodendrocytes. Moreover, in a simple in vivo model of lysophosphatidylcholine-induced demyelination these targeted PNPs induce reparative remyelination with measurable increase of myelin thickness of myelin in individual axons and the overall number of myelinated axons. Collectively, these studies show promise for clinical strategies aiming at myelin repair.

Natural products and new molecules have also been tested in conjunction with NPs in the treatment of MS. As mentioned above, the use of curcumin for the treatment of CNS diseases has attrached much interest in recent years and Mohajeri et al. developed a polymerized nano-curcumin complex to evaluate its effectiveness in the EAE model [132]. This complex attenuates neurological symptoms of EAE by enhancing myelin repair and neuroprotection and downregulation of oxidative processes and inflammation. These findings represent a potentially new therapeutic avenue for this pathology and for the use of natural compounds. Similarly, a recent study carried out by Gammon and colleagues used a polymeric nanocarrier of PHCCC, a small molecule glutamate receptor enhancer from the carboxamides family [133]. This study revealed that this nanosystem reduces activation and secretion of pro-inflammatory cytokines of primary dendritic cells as well as co-cultures of dendritic and T cell. Cytotoxicity is 36-fold less compared with non-encapsulated PHCCC and treatment of EAE animals with PHCCC PNPs delays disease onset and decreases disease severity as compared to treatment with free compound. These results highlight the benefit of controlled delivery of potentially cytotoxic modulators throughout polymeric nanocarriers.

Gene therapy strategies for the treatment of MS have also gained much interest in the recent decades. With relation to nanomedicine, studies have evaluated gene delivery to cells, using genomic DNA, plasmid DNA, siRNA or oligonucleotides, encapsulation into NPs. For instance, Kong et al. have recently developed a DNA-loaded chitosan nanocarrier for enhanced transfection of astrocytes, suggesting the possibility of using nanocarriers loaded with active molecules in combination with genetic material[134]. 
Table 2. Selected pre-clinical studies based on novel drug-loaded polymeric nanoparticles for the treatment of common neurodegenerative diseases. See text for more details.

\begin{tabular}{|c|c|c|c|c|c|c|c|c|}
\hline Disease & $\begin{array}{l}\text { Loaded } \\
\text { molecule }\end{array}$ & Polymeric matrix & $\begin{array}{c}\text { Surface } \\
\text { modifications }\end{array}$ & Dose & $\begin{array}{l}\text { Admin. } \\
\text { route }\end{array}$ & $\begin{array}{c}\text { Animal } \\
\text { Model }\end{array}$ & Results & Ref \\
\hline AD & Curcumin & PLGA & $\begin{array}{l}\text { [Gd]DTPA } \\
\text { Chitosan } \\
\text { IgG4.1 } \\
\text { K16ApoE } \\
\end{array}$ & $100 \mu \mathrm{Ci} / 100 \mu \mathrm{L}$ & i.v. & Tg2576 mice & $\begin{array}{l}\text { Improved BBB transcytosis by } \\
\text { coating with a K16ApoE. } \\
\text { Demonstration of enhanced MRI } \\
\text { contrast to detect } A \beta \text { plaques. }\end{array}$ & [59] \\
\hline AD & EGCG/AA & PLGA & PEG & $40 \mathrm{mg} / \mathrm{kg}$ & v.o. & $\begin{array}{l}\mathrm{APP} / \mathrm{PS} 1 \\
\text { mice }\end{array}$ & $\begin{array}{l}\text { Reduction of neuroinflammation, } \mathrm{A} \beta \\
\text { plaque burden, soluble and insoluble } \\
\mathrm{A} \beta(1-42) \text { peptide levels. } \\
\text { Enhanced synapsis expression, spatial } \\
\text { learning and memory processes. }\end{array}$ & {$[51]$} \\
\hline AD & $\begin{array}{l}\text { Curcumin/ } \\
\text { Selenium }\end{array}$ & PLGA & - & NA & i.v. & 5XFAD mice & Specific binding to $A \beta$ plaques & {$[61]$} \\
\hline AD & DBP & PLGA & - & $2.5 \mathrm{mg} / \mathrm{kg}$ & i.v. & 5XFAD mice & $\begin{array}{l}\text { Inhibition } A \beta \text { aggregation in vitro. } \\
\text { Attenuation of } A \beta \text { accumulation, } \\
\text { neuroinflammation, neuronal loss and } \\
\text { cognitive dysfunction. }\end{array}$ & [72] \\
\hline AD & - & $\begin{array}{c}\text { P(HDCA-co-RCA-coMePEGCA) } \\
\text { (MePEGCA-co-BioPEGCA-co-HDCA) } \\
{ }^{14} \mathrm{C}-\mathrm{P}(\mathrm{HDCA}-\mathrm{co}-\mathrm{MePEGCA})\end{array}$ & Anti-A $\beta 1-42 \mathrm{mAb}$ & $40 \mathrm{mg} / \mathrm{kg}$ & i.v. & $\operatorname{Tg} 2576$ mice & $\begin{array}{l}\text { Complete recovery of memory defect, } \\
\text { reduction of the } A \beta \text { soluble peptide } \\
\text { and its oligomer level in the brain and } \\
\text { increase of plasma } A \beta \text { levels. }\end{array}$ & [79] \\
\hline AD & Zinc & PLGA & g7 & $320 \mu \mathrm{g} Z \mathrm{Zn} / \mathrm{day}$ & i.p. & APP23 mice & $\begin{array}{l}\text { Reduction in plaque size and pro- } \\
\text { inflammatory cytokines IL- } 6 \text { and IL- } \\
18 .\end{array}$ & {$[62]$} \\
\hline AD & DXI & PLGA & PEG & $50 \mathrm{mg} / \mathrm{kg}$ & v.o. & APP/PS1mice & $\begin{array}{l}\text { Memory improvement, reduction of } \\
\text { brain inflammation and } A \beta \text { plaques. }\end{array}$ & {$[65]$} \\
\hline AD & $\mathrm{H} 102$ & PEG-PLA & TGN-QHS & $100-250 \mu \mathrm{g} / \mathrm{kg}$ & i.v. & $\begin{array}{l}\mathrm{APP} / \mathrm{PS} 1 \\
\text { mice }\end{array}$ & $\begin{array}{l}\text { Decrease in tau phosphorylation and } \\
\text { amyloid plaques, increase in A } \beta- \\
\text { degrading enzymes, spatial learning } \\
\text { and memory. Protection of synapses. }\end{array}$ & [71] \\
\hline AD & - & DGLs-PEG & $\begin{array}{l}\text { RVG29 } \\
\text { D-peptide }\end{array}$ & $\begin{array}{l}300 \mu \mathrm{g} \text { DGLs / } \\
\text { day }\end{array}$ & i.v. & $\begin{array}{l}\mathrm{APP} / \mathrm{PS} 1 \\
\text { mice }\end{array}$ & $\begin{array}{l}\text { Down-regulation of key enzyme in } \\
\text { A } \beta \text { formation. Reduction of } \\
\text { neurofibrillary tangles }\end{array}$ & [81] \\
\hline AD & Quercetin & PLGA & - & $20-30 \mathrm{mg} / \mathrm{kg}$ & i.v. & $\begin{array}{l}\text { APP/PS1 } \\
\text { mice }\end{array}$ & $\begin{array}{l}\text { Inhibition of } \mathrm{Zn}^{2+}-\mathrm{A} \beta 42 \\
\text { neurotoxicity. Improved viability of } \\
\text { neurons and cognition and reduction } \\
\text { of memory impairments. }\end{array}$ & [58] \\
\hline
\end{tabular}




\begin{tabular}{|c|c|c|c|c|c|c|c|c|}
\hline AD & H102 & PEG-PLA & $\begin{array}{l}\text { TGN } \\
\text { QHS }\end{array}$ & $40-250 \mu \mathrm{g} / \mathrm{kg}$ & i.v. & $\begin{array}{c}\text { ICR mice } \\
\text { injected with } \\
\mathrm{A} \beta 42\end{array}$ & $\begin{array}{l}\text { Enhanced brain penetration. } \\
\text { Improved spatial learning and } \\
\text { memory. }\end{array}$ & [70] \\
\hline AD & - & Chitosan-PLGA & IgG4.1 & N.A. & - & $\begin{array}{l}\text { MDKC cells } \\
+ \text { A protein }\end{array}$ & $\begin{array}{l}\text { Enhanced BBB uptake } \\
\text { Better interaction with AD } \\
\text { amyloid proteins }\end{array}$ & {$[80]$} \\
\hline Epilepsy & Piperine & Chitosan-STTP & - & $5-10 \mathrm{mg} / \mathrm{kg}$ & i.p. & $\begin{array}{l}\text { PTZ - NMRI } \\
\text { mice }\end{array}$ & $\begin{array}{l}\text { Reduction of latency to onset of } \\
\text { myoclonic jerks and generalized } \\
\text { clonic-tonic seizures, duration of } \\
\text { generalized clonic-tonic seizures and } \\
\text { maximum seizure stage, cell loss and } \\
\text { astrocyte activation. }\end{array}$ & [97] \\
\hline Epilepsy & EGCG & PLGA & PEG & $30 \mathrm{mg} / \mathrm{kg}$ & i.p. & $\begin{array}{c}\mathrm{KA}- \\
\mathrm{C} 57 \mathrm{BL} / 6 \\
\text { mice }\end{array}$ & $\begin{array}{l}\text { Decrease in epileptic episodes and } \\
\text { their intensity, neuronal death and } \\
\text { neuroinflammation }\end{array}$ & [96] \\
\hline Epilepsy & Curcumin & Chitosan-alginate-STTP & - & $12.5-25 \mathrm{mg} / \mathrm{kg}$ & i.p. & $\begin{array}{l}\text { PTZ - NMRI } \\
\text { mice }\end{array}$ & $\begin{array}{l}\text { Anticonvulsant activity by NP } \\
\text { treatment. Prevention of cognitive } \\
\text { impairment. Reduced the level of } \\
\text { glial activation and cell death. }\end{array}$ & [91] \\
\hline Epilepsy & $\begin{array}{c}\text { TRH } \\
\text { analogues }\end{array}$ & PLGA & Chitosan & $20 \mu \mathrm{mol} / \mathrm{kg}$ & i.n. & $\begin{array}{l}\text { PTZ- Sprague } \\
\text { Dawley rats }\end{array}$ & $\begin{array}{l}\text { Increased anti-epileptic effect as } \\
\text { compared to their respective free } \\
\text { drugs. }\end{array}$ & [99] \\
\hline Epilepsy & Curcumin & Chitosan-alginate-STTP & - & $12.5 \mathrm{mg} / \mathrm{kg}$ & i.p. & $\begin{array}{l}\text { PTZ - NMRI } \\
\text { mice }\end{array}$ & $\begin{array}{l}\text { Neuroprotection. } \\
\text { Upregulation of EPO and klotho } \\
\text { levels. } \\
\text { Reduction in mRNA level of TNF- } \alpha .\end{array}$ & [92] \\
\hline Epilepsy & OXC & PLGA & - & $0.5 \mathrm{mg} / \mathrm{kg}$ & i.n. & $\begin{array}{l}\text { PTZ - Wistar } \\
\text { rats }\end{array}$ & $\begin{array}{l}\text { Reduction of the number of required } \\
\text { administrations compared to the free } \\
\text { drug to control seizures. } \\
\text { Neuroprotection. }\end{array}$ & [90] \\
\hline Epilepsy & $\mathrm{CBZ}$ & PLGA & - & $0.7-5 \mathrm{mg} / \mathrm{kg}$ & i.v. & $\begin{array}{l}\text { INH - Wistar } \\
\text { rats }\end{array}$ & $\begin{array}{l}\text { Pgp inhibitor verapamil increases the } \\
\text { anticonvulsant effect of CBZ and } \\
\text { reduced effective dose. } \\
\text { CBZ-NPs display a } 30 \text {-fold increase } \\
\text { in anticonvulsive effect. }\end{array}$ & [88] \\
\hline Epilepsy & PHT & PBCA & - & $35 \mathrm{mg} / \mathrm{kg}$ & i.v. & $\begin{array}{l}\text { Lithium- } \\
\text { Pilocarpine } \\
\text { Sprague- } \\
\text { Dawley rats }\end{array}$ & $\begin{array}{l}\text { Anticonvulsant activity in the PHT- } \\
\text { resistant rats and increase of the ratio } \\
\text { of the AUC of }[\mathrm{PHT}] \text { in the } \\
\text { brain/plasma compared to PHT } \\
\text { treatment. }\end{array}$ & [89] \\
\hline
\end{tabular}




\begin{tabular}{|c|c|c|c|c|c|c|c|c|}
\hline PD & miR-124 & PEI & RVG29 & $\begin{array}{l}20 \mathrm{nM} \text { of miR- } \\
\quad 124\end{array}$ & icv & $\begin{array}{l}\text { MPTP - } \\
\text { C57BL/6 } \\
\text { mice }\end{array}$ & $\begin{array}{l}\text { Inhibition of proinflammatory } \\
\text { signaling and enhanced } \\
\text { neuroprotection. }\end{array}$ & [108] \\
\hline PD & Selegiline & Chitosan-STTP & - & $1 \mathrm{mg} / \mathrm{kg}$ & i.n. & $\begin{array}{l}\text { Rotenone - } \\
\text { Sprague- } \\
\text { Dawley rats }\end{array}$ & $\begin{array}{l}\text { Increase of catalase activity, } \\
\text { dopamine, and glutathione content in } \\
\text { the brain. } \\
\text { Improved performance in locomotor } \\
\text { activity, catalepsy, and stride length } \\
\text { tests. }\end{array}$ & [105] \\
\hline PD & $\mathrm{Pm}$ & Chitosan-STTP & - & $50 \mu \mathrm{L}$ of NPs & i.n. & $\begin{array}{l}\text { Rotenone - } \\
\text { Sprague- } \\
\text { Dawley rats }\end{array}$ & $\begin{array}{l}\text { Improved score of photoactometer } \\
\text { and reduced motor deficit in the form } \\
\text { of catalepsy compared to marketed } \\
\text { tablets. Increased antioxidant and } \\
\text { dopamine level in the brain. }\end{array}$ & [104] \\
\hline PD & SiRNA & PEI & - & $\begin{array}{c}0.75 \mu \mathrm{g} \\
\mathrm{PEI} / \mathrm{siRNA}\end{array}$ & icv & $\begin{array}{l}\text { Thy1-aSyn } \\
\text { mice }\end{array}$ & $\begin{array}{l}\text { Elimination of neuroinflammation in } \\
\text { brain parenchyma and } \\
\text { ependymocytes. } \\
\text { SNCA protein and SNCA mRNA } \\
\text { expression reduced by } 50 \text { and } 65 \% \text {, } \\
\text { respectively, in the striatum. }\end{array}$ & [107] \\
\hline PD & PFCE & PLGA & miR-124 & $\begin{array}{l}200 \mathrm{nM} \\
\mathrm{miR}-124\end{array}$ & icv & $\begin{array}{l}\text { 6-OHDA - } \\
\text { C57BL/6 } \\
\text { mice }\end{array}$ & $\begin{array}{l}\text { Increase of the number of migrating } \\
\text { neuroblasts that reached the granule } \\
\text { cell layer of the olfactory bulb. } \\
\text { Induction of migration of neurons } \\
\text { into the lesioned striatum. } \\
\text { Amelioration of motor symptoms. }\end{array}$ & [109] \\
\hline PD & L-DOPA & PLGA & - & $0.35 \mathrm{mg} / \mathrm{kg}$ & i.n. & $\begin{array}{l}\text { 6-OHDA - } \\
\text { Wistar rats }\end{array}$ & $\begin{array}{l}\text { Coordination in the nano-DOPA } \\
\text { group double of free drug group. } \\
\text { Better effects, half-life and } \\
\text { bioavailability of nano-DOPA. }\end{array}$ & [101] \\
\hline PD & Nicotine & PLGA & - & $1 \mathrm{mg} / \mathrm{kg}$ & i.p. & $\begin{array}{l}\text { MPTP - } \\
\text { Swiss albino } \\
\text { mice }\end{array}$ & $\begin{array}{l}\text { Enhancednicotine bioavailability and } \\
\text { modulation of oxidative stress and } \\
\text { apoptosis. }\end{array}$ & [103] \\
\hline HD & Trehalose & Polyacrylate & $\begin{array}{l}\mathrm{SO}_{3}^{-} \\
\mathrm{NH}_{2} \\
\mathrm{PEG}\end{array}$ & $50 \mu \mathrm{M}$ & i.p. & $\begin{array}{l}\text { B6CBA-Tg } \\
\text { mice } \\
\text { (HDexon1) } \\
62 \mathrm{Gpb} / 3 \mathrm{~J} \\
\end{array}$ & $\begin{array}{l}\text { Inhibition of amyloid aggregation } \\
\text { under extra/intracellular conditions } \\
\text { and suppress of polyglutamine } \\
\text { aggregation. }\end{array}$ & [118] \\
\hline HD & Cholesterol & PLGA & g7 & $\begin{array}{l}\text { 6.3-21 } \mu \mathrm{g} \text { of } \\
\text { colesterol }\end{array}$ & i.p. & R6/2 mouse & $\begin{array}{l}\text { Repeated systemic delivery of g7- } \\
\text { PNPs-Chol rescues synaptic and }\end{array}$ & [120] \\
\hline
\end{tabular}




\begin{tabular}{|c|c|c|c|c|c|c|c|c|}
\hline & & & & & & & $\begin{array}{l}\text { cognitive dysfunction and partially } \\
\text { improves global activity in HD mice }\end{array}$ & \\
\hline HD & si(RNA) & $\beta$-cyclodextrin & - & $2.5 \mu \mathrm{g}$ & $\begin{array}{c}\text { Brain } \\
\text { injections }\end{array}$ & $\begin{array}{l}\mathrm{R} 6 / 2 \text { mouse } \\
\text { model of } \mathrm{HD}\end{array}$ & $\begin{array}{l}\text { Selective alleviation of motor deficits. } \\
\text { Sustained HTT gene knockdown. }\end{array}$ & [121] \\
\hline MS & $\begin{array}{l}\text { Rapamycin } \\
\text { OVA }_{323-339} \\
\text { 2W1S } \\
\text { PLP }_{139-151} \\
\end{array}$ & $\begin{array}{l}\text { PLGA } \\
\text { PLA }\end{array}$ & PEG & $\begin{array}{c}4 \mu \mathrm{g} \\
\text { (peptide) } \\
50 \mu \mathrm{g} \\
\text { (rapamycin) } \\
\end{array}$ & i.v. or s.c. & $\begin{array}{l}\text { SJL mice + } \\
\text { PLP139 } \\
\text { PTx }\end{array}$ & $\begin{array}{l}\text { Therapeutic protection in adoptive, } \\
\text { relapsing EAE. }\end{array}$ & [126] \\
\hline MS & TGF- $\beta 1$ & PLGA & $\begin{array}{c}\text { PEI } \\
\mathrm{MOG}_{40-54 / \mathrm{H}-2 \mathrm{D}^{\mathrm{b}}-\mathrm{Ig}} \\
\text { anti-Fas mAb } \\
\text { PD-L1-Fc } \\
\text { CD47-Fc } \\
\text { streptavidin } \\
\end{array}$ & $\begin{array}{l}1 \mathrm{mg} \mathrm{NPs} \\
\text { /mouse/time } \\
\text { point }\end{array}$ & i.v. & $\begin{array}{l}\text { C57BL/6J } \\
\text { mice }+ \\
\text { MOG }_{35-55} \\
\text { PTx }\end{array}$ & $\begin{array}{l}\text { Amelioration in clinical EAE score, } \\
\text { neuroinflammation and demyelination }\end{array}$ & [130] \\
\hline MS & $\begin{array}{l}\text { DNA } \\
\text { plasmid }\end{array}$ & $\begin{array}{l}\text { Chitosan } \\
\text { PEI }\end{array}$ & PEG & $\begin{array}{c}\text { 1-20 N:P ratio } \\
\text { (pspCS to } \\
\text { pDNA) }\end{array}$ & - & $\begin{array}{l}\mathrm{C} 57 \mathrm{BL} / 6 \\
\text { mice }+ \\
\mathrm{MOG}_{35-55}\end{array}$ & $\begin{array}{l}\text { Very high cell transfection } \\
\text { efficiency. } \\
\text { Transformation of normal astrocytes } \\
\text { to be phagocytic astrocytes. }\end{array}$ & [134] \\
\hline MS & - & PLA & $\begin{array}{l}\text { OVA }_{323-339} \\
\text { PLP }_{139-151} \\
\text { E } \alpha_{52-68}\end{array}$ & $1.25 \mathrm{mg}$ PLA & i.v. & $\begin{array}{l}\text { SJL/J mice + } \\
\text { PLP }_{139-151}\end{array}$ & $\begin{array}{l}\text { Suppression of inflammatory } \\
\text { signalling pathways, decreases in } \\
\text { positive co-stimulatory molecules } \\
\text { (CD86, CD80, and CD40), reduction } \\
\text { of T cell proliferation, increase of T } \\
\text { cell apoptosis, and a stronger anti- } \\
\text { inflammatory response. }\end{array}$ & [128] \\
\hline MS & - & PLA & $\begin{array}{l}\text { OVA }_{323-339} \\
\text { PLP }_{139-151} \\
\text { PLP }_{178-191}\end{array}$ & $\begin{array}{c}1.25 \mathrm{mg} \text { of } \\
\text { acNP-OVA } 323- \\
339(8 \mathrm{mg} / \mathrm{mg} \\
\text { OVA }_{323-339)}\end{array}$ & s.c. & $\begin{array}{l}\text { SJL/J mice + } \\
\text { PLP139-151 } \\
\text { PLP } 178-191\end{array}$ & $\begin{array}{l}\text { Improved mean clinical disease } \\
\text { scores compared. }\end{array}$ & [129] \\
\hline MS & PHCCC & PLGA & - & $3 \mathrm{mg} / \mathrm{kg}$ & s.c. & $\begin{array}{l}\text { C57BL/6 } \\
\text { mice }+ \\
\text { MOG }_{35-55} \\
\text { PTx }\end{array}$ & $\begin{array}{l}\text { Free PHCCC 36-fold more toxic than } \\
\text { PHCCC-loaded NPs. Treatment of } \\
\text { mice with PHCCC NPs decreases } \\
\text { disease severity and delays disease } \\
\text { onset compared with that of free drug. }\end{array}$ & [133] \\
\hline MS & $\begin{array}{l}\text { Rapamycin } \\
\text { OVA }_{323-339} \\
\text { PLP }_{139-151}\end{array}$ & $\begin{array}{l}\text { PLGA } \\
\text { PLA }\end{array}$ & PEG & $\begin{array}{c}10 \mu \mathrm{g} \\
\text { Rapamycin }\end{array}$ & s.c. or i.v. & $\begin{array}{l}\text { SJL mice + } \\
\text { PLP139-151 } \\
\text { PTx }\end{array}$ & $\begin{array}{l}\text { Rapamycin-loaded NPs induce } \\
\text { immunological tolerance. Inhibition } \\
\text { of antigen-specific hypersensitivity } \\
\text { reactions, CD4+, CD8+ and T-cell }\end{array}$ & [127] \\
\hline
\end{tabular}




\begin{tabular}{|c|c|c|c|c|c|c|c|c|}
\hline & & & & & & & $\begin{array}{l}\text { activation. Increase in regulatory cells } \\
\text { numbers and in tolerance of B-cell to } \\
\text { multiple immunogenic challenges. }\end{array}$ & \\
\hline MS & Curcumin & NA & - & $12.5 \mathrm{mg} / \mathrm{kg}$ & i.p. & $\begin{array}{c}\text { Lewis rats + } \\
\text { GPSCH } \\
\text { PTx }\end{array}$ & $\begin{array}{l}\text { Correction of balance of pro- } \\
\text { inflammatory and anti-inflammatory } \\
\text { genes expression, } \\
\text { improved re-myelination, increased } \\
\text { progenitor cell markers and decrease } \\
\text { of oxidative stress and scores of } \\
\text { disease in therapeutic and } \\
\text { prophylactic administration. }\end{array}$ & [132] \\
\hline MS & Mouse LIF & PLGA & $\begin{array}{l}\text { Avidin } \\
\text { NG-2 }\end{array}$ & $\begin{array}{c}2 \mu 1 \text { of } 3 \mathrm{mg} / \mathrm{ml} \\
\text { of NPs }\end{array}$ & i.v. & $\begin{array}{c}\mathrm{C} 57 \mathrm{Bl} / 6 \text { male } \\
\text { mice + LPC }\end{array}$ & Increased myelin repair. & [131] \\
\hline
\end{tabular}

Anti-Aß1-42 mAb, Anti-Aß1-42 monoclonal antibody; ${ }^{14}$ C-P(HDCA-co-MePEGCA), radio-labeled 14C-P(HDCAco-MePEGCA) copolymer; CBZ, carbamazepina;

Coumarin-C75, coumarin-based monoamine oxidase B inhibitor; CPS-A, Meningococcal capsular polysaccharide antigen from serogroup A: DBP, vitamin-D binding protein; CaMe, candidal meningitis; CrMe, cryptococcal meningitis; DGLs, dendrigraft poly-L-lysines; D-peptide, disruption p-tau associated fibril formation peptide; EAE, experimental autoinmune encephalomyelitis; g7, 7 aminoacids glycopeptide for BBB crossing; GBM, glioblastoma; [Gd]DTPA, gadolinium-diethylene triamine pentaacetic acid; GPSCH, guinea pig spinal cord homogenate; H102, $\beta$-sheet breaker peptide H102; IgG4.1, human anti-amyloid antibody IgG4.; INH, chemoconvulsant isoniazid; K16ApoE, cationic BBB penetrating peptide; KA, kainic acid; LIF, leukaemia inhibitory factor; LPC, myelin toxin lysophosphatidylcholine: LPS, lipopolysaccharides from P. aeruginosa; MDKC, Madin-Darby Canine Kidney cells; (MePEGCA-co-BioPEGCA-co-HDCA), poly[methoxypoly(ethylene glycol) cyanoacrylate-co-Biotinpoly(ethylene glycol) cyanoacrylate-co-hexadecyl cyanoacrylate] copolymer; miR-124, microRNA-124; MPTP, 1-Methyl-4-phenyl-1,2,3,6-tetrahydropyridine; NG-2, antibodies against NG-2 chondroitin sulfate proteoglycan; 6-OHDA, 6-hydroxydopamine; OVA, ovalbumin peptide; OX26, anti-transferrin receptor antibody; PAA, Poly(aspartic acid); PBAE, poly(beta-amino ester); PBCA, poly(-butylcyanoacrylate); PEG-poly(PDL-co-DO), PEGylated-Poly(u-pentadecalactone-co-p-dioxanone); PEI, polyethylenimine; PFCE, perfluoro-1,5-crown ether; PHCCC, N-Phenyl-7-(hydroxyimino)cyclopropa[b]chromen-1a-carboxamide; P(HDCA co-RCA-coMePEGCA), Poly[(hexadecyl cyanoacrylate- co-rhodamine B cyanoacrylate-co-methoxypoly(ethylene glycol cyanoacrylate)] copolymer; PHT, phenytoin; PLGA-PLL, Poly(D,L-lactideco-glycolide)- poly(e-carbobenzoxylL-lysine); Pm, pramipexole; QHS, brain-targeting peptide; RVG29, brain-targeted gene; Si.RNA, small interfering RNAs; SPIO, superparamagnetic iron oxide; STTP, sodium tripolyphosphate; T7, human transferrin receptor-binding peptide; TGF- $\beta 1$, transforming growth factor- $\beta 1$; TGN, brain-targeting peptide; TRH, Thyrotropin releasing hormone. 


\section{NANOTECHNOLOGY IN CLINICAL TRIALS OF NEURODEGENERATIVE DISEASES.}

Although NPs provide many advantages for the controlled delivery of drugs, there are drawbacks that condition their applicability in the clinic. Most prominent amongst these are challenges linked to industrial scaling-up of their manufacturing and complex regulatory approval [135]. However, there are clinical trials that have started to evaluate the therapeutic potential of several nanotechnological devices for neurodegenerative diseases.

A phase 2 clinical trial (NCT03806478) will assess the safety, tolerability and efficacy of intranasal delivery of APH-1105 NPs for the treatment of mild to moderate AD in adults [136]. This study, which will be multi-center, randomized, triple blind placebo-control with parallel groups, is set to initiate recruiting.

Other trials employing NPs but not in an interventional setting are more advanced. An exploratory clinical trial (NCT01246336) has been completed in 2017 and used nanotechnology to detect biomarkers of PD from exhaled breath [137]. Primary outcomes were to analyze combinations of nanomaterial-based sensors, namely organically functionalized carbon nanotubes and gold nanoparticles, but results of this trial have not yet been reported. Another clinical phase 2 trial related to PD utilising 31P-MRS imaging is currently in the recruiting phase (NCT03815916) [138]. It is designed as a singlecenter open label pilot, sequential group, investigator blinded study and will assess the CNS metabolic effects, safety, pharmacokinetics, and pharmacodynamics of gold nanocrystals (CNM-Au8) in patients with PD. A similar clinical trial has also been performed in patients with MS: This phase 2 clinical trial (NCT03993171) is also based on 31P-MRS imaging and will assess the CNS metabolic effects, safety, pharmacokinetics, and pharmacodynamics of CNM-Au8 in patients who have been diagnosed with MS within fifteen years of screening [139]. This study, designed as singlecenter open label, sequential group, investigator and patient blinded, is also currently in recruiting phase. Finally, a phase 1 clinical trial (NCT02511028), which was completed in 2019, aimed at the in vivo characterization of inflammation with ferumoxytol, an ultrasmall superparamagnetic iron oxide nanoparticle [140]. The primary outcome of this trial is to determine if ferumoxytol induces long-lasting brain signal intensity changes in healthy volunteers and individuals with MS. Results of this study are yet to be reported. 


\section{Conclusions}

The rise in the number of individuals affected by neurodegenerative diseases constitutes an important socioeconomic health problem around the world and is mainly due to the progressive aging of populations and the lack of effective therapies. Even when promising therapeutic molecules are available their restricted delivery to the brain at therapeutically meaningful levels compromises their reaching full clinical potential. Thus, finding clinically feasible entry points from the blood to the CNS is one of the most formidable challenges of current neurovascular research.

As reviewed herein, nanotechnology has opened new therapeutic opportunities in this field and there is very good evidence that, amongst the many different controlled release systems, PNPs constitute one of the best alternatives. These vehicles are safe for drug administration due to their inherent biodegradability, biocompatibility, easy elimination and non-toxicity [38]. However, the use of organic solvents during the manufacturing process of PNPs is one of the most important disadvantages and currently limits their biomedical application, namely because of possible increased toxicity [141]. In that regard lipid-based nanocarriers could be an interesting alternative, since the use of organic solvents is not strictly necessary for manufacture. Furthermore, they are produced with natural-based lipids, which are often very similar to BBB membrane composition $[27,142,143]$. Nevertheless, PNPs exhibit a high loading capacity and their surfaces and matrix are easily modified by targeting and penetrating molecules. All in all, the use of polymer-type nanostructured systems for the controlled delivery of drugs into CNS continues to be a pharmacological strategy of great interest in the field of nanomedicine in recent years. The intrinsic versatility provided by these systems not only provide novel alternatives for many neurological diseases, but also allow rapid and effective pre-clinical assessment of such alternative treatment modalities.

\section{Future perspectives}

Research in the next few years will increasingly focus on elucidating the multifactorial etiology of neurodegenerative diseases and molecular pathways involved in their pathogenesis. Likewise, a better understanding of the physiology and molecular regulation of the BBB will help in overcoming its intrinsic restrictions to efficient CNS drug delivery. Whilst polymeric nanocarriers are undoubtedly among the best tools to overcome CNS delivery problems, clinical translation of nanocarriers-based treatments 
remains a challenging and expensive challenge for the pharmaceutical industry. As such nanotechnology has not yet entered mainstream clinical practice. Stringent protocols of validation of in vitro and in vivo protocols are necessary to facilitate translation from bench to the clinical trials. Likewise, challenges for large scale manufacturing require innovation from chemists and engineers and regulatory policies have to be adapted to facilitate access to trials and patients. Thus despite tremendous progress in basic and preclinical research, the translation of these nanovehicles to clinical practice remains one of the most ambitious challenges in this field, and will be a major focus of most nanomedicine trials in the next decade.

\section{Executive summary}

Neurodegenerative diseases comprise a wide variety of pathologies with a high socioeconomic impact.

- Most recent global reports estimate that neurological diseases cause around 250 million DALYs and 9 million deaths worldwide.

- There are currently 47.5 million people with dementia worldwide, with incidence increasing exponentially with age for the over 65 .

- Higher life expectancy and aging of the population worldwide has increased the prevalence of neurodegenerative disorders over recent decades.

- The most common neurodegenerative disorders are Alzheimer's disease, epilepsy, Parkinson's disease, multiple sclerosis and Huntington's disease.

\section{Therapeutic success for neurodegenerative diseases is limited}

- Unclear etiology and ineffectiveness of available treatments renders these pathologies currently uncurable.

- Blood-brain barrier permeability restrictions, central nervous system complexity, late diagnoses and paucity of animals modelling the human disease limit our understanding of neurodegeneration.

Nanomedicine offers promising novel tools for the treatment of neurodegenerative diseases 
- Polymeric nanoparticles, developed as controlled drug delivery systems, constitute a suitable alternative to overcome problems of brain bioavailability associated with many drugs and enhance their inherent effectiveness.

- The latest advances in polymeric nanoparticles design, including surface modification and targeting strategies, have been applied to developing novel treatment modalities for most prevalent chronic neurodegenerative diseases.

Current pre-clinical studies of novel polymeric nanocarriers for the treatment of most common neurodegenerative diseases.

- Recent pre-clinical studies, described in this review, demonstrate the potential of polymeric nanoparticles based-therapies for the treatment of several neurodegenerative diseases, and report promising results in the field of CNS drug delivery, indicating novel opportunities for future therapeutic approaches for neurodegenerative disorders.

\section{Conflict of interest}

None of the authors have any conflicts of interest including any financial, personal or other relationships with other people or organizations. All authors have reviewed the contents of the manuscript being submitted and approved its contents.

\section{References}

Reference note: indicated references are '*' - of interest and “**” - of considerable interest.

1. **Wyss-Coray T. Ageing, neurodegeneration and brain rejuvenation. Nature. 539, 180-186 (2016).

Comprehensive and well described explanation of neurodegeneration and its development.

2. Liu Z, Zhou T, Ziegler AC, Dimitrion P, Zuo L. Oxidative Stress in Neurodegenerative Diseases : From Molecular Mechanisms to Clinical Applications. Oxid Med Cell Longev.2017, 1-11 (2017).

3. Cicero CE, Mostile G, Vasta R, et al. Metals and neurodegenerative diseases . A systematic review. Enviro Res. 159, 82-94 (2017).

4. ** Feigin VL, Abajobir AA, Abate KH, et al. Global, regional, and national burden of neurological disorders during 1990 - 2015: a systematic analysis for the Global Burden of Disease Study 2015. Lancet Neurol. 16, 877-897 (2017).

Latest data on global, regional, and national burden of neurological disorders 
worldwide.

5. World Health Organization (WHO) [Internet]. (2019). Available from: https://www.who.int/features/qa/55/en/.

6. Nichols E, Szoeke CEI, Vollset SE, et al. Global, regional, and national burden of Alzheimer' s disease and other dementias , 1990 - 2016 : a systematic analysis for the Global Burden of Disease Study 2016. Lancet Neurol. 18, 88106 (2019).

7. Beghi E, Giussani G, Nichols E, et al. Global , regional, and national burden of epilepsy , 1990 - 2016 : a systematic analysis for the Global Burden of Disease Study 2016. Lancet Neurol. 18, 357-75 (2019).

8. Bill F, Foundation MG. Global, regional and national burden of Parkinson's disease, 1990 - 2016 : a systematic analysis for the Global Burden of Disease Study 2016. Lancet Neurol. 17, 939-953 (2018).

9. Wallin MT, Culpepper WJ, Nichols E, et al. Global, regional, and national burden of multiple sclerosis 1990 - 2016 : a systematic analysis for the Global Burden of Disease Study 2016. Lancet Neurol.. 18, 269-285 (2019).

10. Logroscino G, Piccininni M, Marin B, et al. Global, regional, and national burden of motor neuron diseases 1990 - 2016 : a systematic analysis for the Global Burden of Disease Study 2016. Lancet Neurol. 17, 1083-1097 (2018).

11. Tan EK, Srivastava AK, Arnold WD, Singh MP, Zhang Y. Neurodegeneration : Etiologies and New Therapies. BioMed Res Int. 2015(1-2) (2015).

12. Pezeshgi H, Janmaleki M, Novin M, Saliba J, El-hajj F. In vitro models and systems for evaluating the dynamics of drug delivery to the healthy and diseased brain. J Controlled Release. 273, 108-130 (2018).

13. Zenaro E, Piacentino G, Constantin G. Neurobiology of Disease The blood-brain barrier in Alzheimer's disease. Neurobiology of Disease. 107, 41-56 (2017).

14. Palmer A. The role of the blood brain barrier in neurodegenerative disorders and their treatment. J Alzheimers Dis. 24(4), 643-656 (2011).

15. Ash PEA, Vanderweyde TE, Youmans KL, Apicco DJ. Pathological Stress Granules in Alzheimer' s Disease. Brain Res. 1584, 52-58 (2014).

16. Caccamo A, Magrì A, Medina DX, et al. mTOR regulates tau phosphorylation and degradation: implications for Alzheimer's disease and other tauopathies. Aging Cell. 12(3), 370-380 (2014).

17. Pickford F, Masliah E, Britschgi M, et al. The autophagy-related protein beclin 1 shows reduced expression in early Alzheimer disease and regulates amyloid $\beta$ accumulation in mice. J Clin Invest. 118(6), 2190-2199 (2008).

18. Newman AB, Murabito JM. The Epidemiology of Longevity and Exceptional Survival. Epidemiol Rev. 35, 181-197 (2013).

19. Sebastiani P, Bae H, Sun FX, et al. Meta - analysis of genetic variants associated with human exceptional longevity. Aging. 5(9), 653-661 (2013).

20. Podtelezhnikov AA, Tanis KQ, Nebozhyn M, Ray WJ, Stone DJ, Loboda AP. Molecular Insights into the Pathogenesis of Alzheimer' s Disease and Its Relationship to Normal Aging. PLoS One. 6(12), e29610 (2011).

21. Hernandez DG, Nalls MA, Gibbs JR, et al. Distinct DNA methylation changes highly correlated with chronological age in the human brain. Human Molecular Genetics. 20(6), 1164-1172 (2011).

22. Horvath S, Ritz BR. Increased epigenetic age and granulocyte counts in the blood of Parkinson' s disease patients. Aging. 7(12), 1130-1142 (2015).

23. Jager PL De, Srivastava G, Lunnon K, Burgess J, Schalkwyk LC, Yu L.

Alzheimer's disease: early alterations in brain DNA methylation at ANK1, BIN1, 
RHBDF2 and other loci. Nat Neurosc 17(9), 1156-1163 (2015).

24. Pardridge WM. Drug transport across the blood - brain barrier. J Cereb Blood Flow Metab. 32(11), 1959-1972 (2012).

25. Warren KE. Beyond the Blood-Brain Barrier: The importance of Central Nervous System (CNS) Pharmacokinetics for the Treatment of CNS Tumors, including Diffuse intrinsic Pontine Glioma. Front Oncol. 8, 1-11 (2018).

26. Wolff A, Antfolk M, Brodin B, Tenje M. In Vitro Blood - Brain Barrier Models - An Overview of Established Models and New Microfluidic Approaches. J Pharm Sci. 104(9), 2727-2746 (2015).

27. *Tajes M, Ramos-fernández E, Weng-jiang X, et al. The blood-brain barrier: Structure , function and therapeutic approaches to cross it. $\mathrm{Mol}$ Memb Biol. 31(5), 152-167 (2014).

Comprehensive and well described explanation of blood-brain barrier structure and function.

28. Chen Y, Liu L. Modern methods for delivery of drugs across the blood - brain barrier. Adv Drug Deliv Rev. 64(7), 640-665 (2012).

29. *Banks WA. From blood - brain barrier to blood - brain interface : new opportunities for CNS drug delivery. Nat RevDrug Discov. 15(4), 275-292 (2016).

Comprehensive and well described explanation about the recent knowledge of blood-brain barrier features as a novel strategy for brain drug delivery.

30. Ballard C, Gauthier S, Corbett A, Brayne C, Aarsland D, Jones E. Alzheimer's disease. The Lancet. 377(9770), 1019-1031 (2011).

31. Cao J, Hou J, Ping J, Cai D. Advances in developing novel therapeutic strategies for Alzheimer' s disease. Mol Neurodegener. 13(64), 1-20 (2018).

32. Brown RC, Lockwood AH, Sonawane BR. Neurodegenerative Diseases : An Overview of Environmental Risk Factors. Environ Health Perspect. 113(9), 1250-1256 (2005).

33. Agrawal M, Biswas A, Levy CE. Molecular diagnostics of neurodegenerative disorders. Front Mol Biosci. 2, 1-10 (2015).

34. Legname G. Novel Approaches to Diagnosis and Therapy in Neurodegenerative Diseases. 5th Internat Conf Biomed Engin Vietnam. Proceeding, 155-158 (2015).

35. Gitler AD, Dhillon P, Shorter J. Neurodegenerative disease : models , mechanisms , and a new hope. Dis Mod \& Mech. 10, 499-502 (2017).

36. Castillo X, Castro-obregón S, Gutiérrez-becker B, et al. Re-thinking the Etiological Framework of Neurodegeneration. Front Neurosci. 13, 1-25 (2019).

37. Andrieux K, Couvreur P. Nanomedicine as a promising approach for the treatment and diagnosis of brain diseases: The example of Alzheimer' s disease. Ann Pharm Fr. 71(4), 225-233 (2013).

38. *Kumari A, Yadav SK, Yadav SC. Biodegradable polymeric nanoparticles based drug delivery systems. Colloids Surf B Biointerfaces. 75, 1-18 (2010). Complete and detaled overview of biodegradable polymeric nanoparticles.

39. *Wilczewska AZ, Niemirowicz K, Markiewicz KH, Car H. Nanoparticles as drug delivery systems. Pharmacological Reports. 64(5), 1020-1037 (2012). Complete and detaled overview of different nanoparticles as drug delivery systems.

40. Wischke C, Schwendeman SP. Principles of encapsulating hydrophobic drugs in PLA / PLGA microparticles. Int J Pharm. 364, 298-327 (2008).

41. Soppimath KS, Aminabhavi TM, Kulkarni AR. Biodegradable polymeric nanoparticles as drug delivery devices. J Controlled Release. 70, 1-20 (2001). 
42. Rao JP, Geckeler KE. Polymer nanoparticles: Preparation techniques and sizecontrol parameters. Prog Polym Sci. 36(7), 887-913 (2011).

43. Masserini M. Nanoparticles for Brain Drug Delivery. ISRN Biochemistry. 2013, 1-18 (2013).

44. *El-say KM, El-sawy HS. Polymeric nanoparticles : Promising platform for drug delivery. Int J Pharm. 528(1-2), 675-691 (2017).

Complete and detaled overview of polymeric nanoparticles as a promising platform for drug delivery

45. Dan G, Mihai A, Bejenaru C, Everard L. Polymeric protective agents for nanoparticles in drug delivery and targeting. Int J Pharm. 510(2), 419-429 (2016).

46. Georgieva J V, Hoekstra D, Zuhorn IS. Smuggling Drugs into the Brain: An Overview of Ligands Targeting Transcytosis for Drug Delivery across the. Pharmaceutics. 6, 557-583 (2014).

47. Tosi G, Ruozi B, Belletti D. Nanomedicine: the future for advancing medicine and neuroscience. Nanomedicine (Lond). 7(8), 1113-1116 (2012).

48. Tosi G, Musumeci T, Ruozi B, et al. The " fate" of polymeric and lipid nanoparticles for brain delivery and targeting: Strategies and mechanism of blood e brain barrier crossing and traf fi cking into the central nervous system. $J$ Drug Deliv Sci Technol. 32, 66-76 (2016).

49. Gao H. Progress and perspectives on targeting nanoparticles for brain drug delivery. Acta Pharm Sin B. 6(4), 268-286 (2016).

50. *Saraiva C, Praça C, Ferreira R, Santos T, Ferreira L, Bernardino L. Nanoparticle-mediated brain drug delivery: Overcoming blood - brain barrier to treat neurodegenerative diseases. J Controlled Release. 235, 34-47 (2016).

Complete and detaled overview of nanoparticles as a promising platform to treat neurodegenrative diseases

51. Cano A, Ettcheto M, Chang J, et al. Dual-drug loaded nanoparticles of Epigallocatechin-3-gallate ( EGCG )/ Ascorbic acid enhance therapeutic efficacy of EGCG in a APPswe / PS1dE9 Alzheimer' s disease mice model. $J$ Controlled Release. 301, 62-75 (2019).

52. Cai Q, Wang L, Deng G, Liu J, Chen Q, Chen Z. Systemic delivery to central nervous system by engineered PLGA nanoparticles. Am J Transl Res. 8(2), 749764 (2016).

53. Zhang T, Lip H, He C, et al. Multitargeted Nanoparticles Deliver Synergistic Drugs across the Blood - Brain Barrier to Brain Metastases of Triple Negative Breast Cancer Cells and Tumor-Associated Macrophages. Adv Healthc Mater. 1900543, 1-15 (2019).

54. Cummings JL, Isaacson RS, Schmitt FA, Velting DM. A practical algorithm for managing Alzheimer' s disease: what, when , and why? Ann Clin Transl Neurol. 2(3), 307-323 (2015).

55. Prince PM, Prince M, Prince M, et al. World Alzheimer Report 2016 Improving healthcare for people living with dementia. (2016).

56. Anand R, Dip K, Ali A. Therapeutics of Alzheimer's disease : Past, present and future. Neuropharmacology. 76, 27-50 (2014).

57. Huang WJ, Zhang X, Chen W. Role of oxidative stress in Alzheimer's disease. Biomed Reports. 4, 519-522 (2016).

58. Sun D, Li N, Zhang W, et al. Design of PLGA-functionalized quercetin nanoparticles for potential use in Alzheimer' s disease. Colloids Surf B 
Biointerfaces. 148, 116-129 (2016).

59. Ahlschwede KM, Curran GL, Rosenberg JT, et al. Cationic carrier peptide enhances cerebrovascular targeting of nanoparticles in Alzheimer' s disease brain. Nanomedicine. 16, 258-266 (2019).

60. Loef M, Schrauzer GN, Walach H, Office E, Oder F. Selenium and Alzheimer' s Disease : A Systematic Review. J Alzheimers Dis. 26, 81-104 (2011).

61. Huo X, Zhang Y, Jin X, Li Y, Zhang L. A novel synthesis of selenium nanoparticles encapsulated PLGA nanospheres with curcumin molecules for the inhibition of amyloid $\beta$ aggregation in Alzheimer' s disease. J Photochem Photobiol B. 190(333), 98-102 (2019).

62. Vilella A, Belletti D, Katrin A, et al. Reduced plaque size and in $\mathrm{fl}$ ammation in the APP23 mouse model for Alzheimer's disease after chronic application of polymeric nanoparticles for CNS targeted zinc delivery. J Trace Elem Med Biol. 49, 210-221 (2018).

63. Mizuno T. The Biphasic Role of Microglia in Alzheimer's Disease. Int J Alzheimers Dis. 2012(737846), 1-9 (2012).

64. Calsolaro V, Edison P. Neuroinflammation in Alzheimer' s disease : Current evidence and future directions. Alzh \& Dement. 12(6), 719-732 (2016).

65. Sánchez-lópez E, Ettcheto M, Egea MA, et al. New potential strategies for Alzheimer's disease prevention : pegylated biodegradable dexibuprofen nanospheres administration to APPswe / PS1dE9. Nanomedicine. 13(3), 11711182 (2017).

66. Hemonnot A, Hua J, Ulmann L, Hirbec H. Microglia in Alzheimer Disease: Well-Known Targets and New Opportunities. Front Aging Neurosc. 11, 1-20 (2019).

67. Condello C, Yuan P, Grutzendler J. Microglia-Mediated Neuroprotection, TREM2, and Alzheimer's Disease: Evidence From Optical Imaging. Biol Psych. 83(4), 377-387 (2018).

68. Streit WJ, Xue Q. Alzheimer' s disease, neuroprotection, and CNS immunosenescence. Front Pharm. 3, 1-7 (2012).

69. Parbo P, Madsen LS, Ismail R, et al. Low plasma neurofilament light levels associated with raised cortical microglial activation suggest inflammation acts to protect prodromal Alzheimer' s disease. Alzh Res Ther. 12(3), 1-7 (2020).

70. Zhang C, Zheng X, Wan X, et al. The potential use of H102 peptide-loaded dualfunctional nanoparticles in the treatment of Alzheimer' s disease. $J$ Controlled Release. 192, 317-324 (2014).

71. Zheng X, Zhang C, Guo Q, Wan X, Shao X, Liu Q. Dual-functional nanoparticles for precise drug delivery to Alzheimer' s disease lesions: Targeting mechanisms , pharmacodynamics and safety. Int J Pharm. 525(1), 237-248 (2017).

72. Jeon SG, Cha M, Kim J, et al. Vitamin D-binding protein-loaded PLGA nanoparticles suppress Alzheimer's disease-related pathology in 5XFAD mice. Nanomedicine. 17, 297-307 (2019).

73. Schwartz M, Ramos JMP. A 20-Year Journey from Axonal Injury to Neurodegenerative Diseases and the Prospect of Immunotherapy for Combating Alzheimer's Disease. J Immunol. 204, 243-250 (2020).

74. Kohyama K, Matsumoto Y. Alzheimer' s disease and immunotherapy: what is wrong with clinical trials ? Immuno Targ Ther. 4, 27-34 (2015).

75. Panza F, Lozupone M. Amyloid- $\beta$ Immunotherapy for Alzheimer Disease : Is It Now a Long Shot? Ann Neurol. 85, 303-315 (2019). 
76. Overk C, Masliah E. Could changing the course of Alzheimer's disease pathology with immunotherapy prevent dementia ? Brain. 142(7), 1853-1855 (2019).

77. Bittar A, Bhatt N, Kayed R. Advances and considerations in AD tau-targeted immunotherapy. Neurobiol Dis. 134, 104707 (2020).

78. Poduslo JF, Hultman KL, Curran GL, et al. Targeting Vascular Amyloid in Arterioles of Alzheimer Disease Transgenic Mice with Amyloid Beta Protein Antibody-Coated Nanoparticles. J Neuropathol Exp Neurol. 70(8), 653-661 (2011).

79. Carradori D, Balducci C, Re F, et al. Antibody-functionalized polymer nanoparticle leading to memory recovery in Alzheimer's disease-like transgenic mouse model. Nanomedicine. 14(2), 609-618 (2018).

80. Jaruszewski K, Ramakrishnan S, Poduslo J, Kandimalla K. Chitosan Enhances the Stability and Targeting of ImmunoNanovehicles to Cerebro-vascular Deposits of Alzheimer's Disease Amyloid Protein. Nanomedicine. 8(2), 250-260 (2012).

81. Liu Y, An S, Li J, et al. Brain-targeted co-delivery of therapeutic gene and peptide by multifunctional nanoparticles in Alzheimer' s disease mice. Biomaterials. 80, 33-45 (2016).

82. Manford M. Recent advances in epilepsy. J Neurology. 264(8), 1811-1824 (2017).

83. Farrell J, Wolff M, Teskey G. Neurodegeneration and Pathology in Epilepsy: Clinical and Basic Perspectives. Adv Neurobiol. 15, 317-334 (2017).

84. Ali N, Nabi M. The Prevalence, Incidence and Etiology of Epilepsy. Int J Clin Exp Neurol. 2(2), 29-39 (2014).

85. Murray C, Vos T, Lozano R, et al. Disability-adjusted life years (DALYs) for 291 diseases and injuries in 21 regions, 1990-2010: a systematic analysis for the Global Burden of Disease Study 2010. The Lancet. 380(2197-2223) (2012).

86. Brodie MJ. Antiepileptic drug therapy the story so far. Seizure. 19(10), 650-655 (2010).

87. Kaur H, Kumar B, Medhi B. Antiepileptic drugs in development pipeline : A recent update. eNeurologicalSci. 4, 42-51 (2016).

88. Zybina A, Anshakova A, Malinovskaya J, et al. Nanoparticle-based delivery of carbamazepine: A promising approach for the treatment of refractory epilepsy. Int J Pharm. 547(1-2), 10-23 (2018).

89. Fang Z, Chen S, Qin J, et al. Pluronic P85-coated poly ( butylcyanoacrylate ) nanoparticles overcome phenytoin resistance in P-glycoprotein overexpressing rats with lithium-pilocarpine-induced chronic temporal lobe epilepsy. Biomaterials. 97, 110-121 (2016).

90. Musumeci T, Francesca M, Pellitteri R, et al. Oxcarbazepine free or loaded PLGA nanoparticles as e ff ective intranasal approach to control epileptic seizures in rodents. Eur J Pharm Biopharm. 133, 309-320 (2018).

91. Hashemian M, Anissian D, Ghasemi-kasman M, et al. Curcumin-loaded chitosan-alginate-STPP nanoparticles ameliorate memory de fi cits and reduce glial activation in pentylenetetrazol-induced kindling model of epilepsy. Prog Neuropsychopharmacol Biol Psychiatry. 79, 462-471 (2017).

92. Rostami S, Hashemian M, Khalili-fomeshi M. Upregulation of klotho and erythropoietin contributes to the neuroprotection induced by curcumin-loaded nanoparticles in experimental model of chronic epilepsy. Brain Res Bull. 142, 281-288 (2018). 
93. Chowdhury A, Sarkar J, Chakraborti T, Pramanik PK, Chakraborti S. Protective role of epigallocatechin-3-gallate in health and disease : A perspective. Biomed Pharm. 78, 50-59 (2016).

94. Noor NA, Mohammed HS, Khadrawy YA, Aboul HS, Radwan NM. Evaluation of the neuroprotective effect of taurine and green tea extract against oxidative stress induced by pilocarpine during status epilepticus. J Basic Appl Zoology. 72, 8-15 (2015).

95. Xie T, Wang W, Mao Z, et al. Effects of epigallocatechin-3-gallate on pentylenetetrazole-induced kindling, cognitive impairment and oxidative stress in rats. Neuros Lett. 516(2), 237-241 (2012).

96. Cano A, Ettcheto M, Espina M, et al. Epigallocatechin-3-gallate loaded PEGylated-PLGA nanoparticles: A new anti-seizure strategy for temporal lobe epilepsy. Nanomedicine. 14(4), 1073-1085 (2018).

97. Anissian D, Ghasemi-kasman M, Khalili-fomeshi M. Piperine-loaded chitosanSTPP nanoparticles reduce neuronal loss and astrocytes activation in chemical kindling model of epilepsy. Int J Biol Macromol. 107, 973-983 (2018).

98. de Gortari P, Uribe R, García-Vázquez A, et al. Amygdala kindling differentially regulates the expression of the elements involved in TRH transmission. Neurochem Int. 41(1), 31-42 (2006).

99. Kaur S, Manhas P, Swami A, Bhandari R, Sharma KK. Bioengineered PLGAchitosan nanoparticles for brain targeted intranasal delivery of antiepileptic TRH analogues. Chem Eng J. 346, 630-639 (2018).

100. Vitale C, Amboni M, Erro R, et al. Parkinson's disease management and impulse control disorders: current state and future perspectives. Exp Rev Neurotherapeutics. 19(6), 495-508 (2019).

101. Gambaryan PY, Kondrasheva IG, Severin ES, Guseva AA, Kamensky AA. Increasing the Efficiency of Parkinson' s Disease Treatment Using a poly (lacticco-glycolic acid) (PLGA) Based L-DOPA Delivery System. ExpNeurobiol. 23(3), 246-252 (2014).

102. Kuo Y, Rajesh R. Current development of nanocarrier delivery systems for Parkinson's disease pharmacotherapy. J Taiwan Inst Chem Eng. 87, 15-25 (2018).

103. Tiwari M, Agarwal S, Bhatnagar P, et al. Nicotine-encapsulated poly(lactic-coglycolic) acid nanoparticles improve neuroprotective efficacy against MPTPinduced parkinsonism. Free Rad Biol Med. 65, 704-718 (2013).

104. Raj R, Wairkar S, Sridhar V, Gaud R. Pramipexole dihydrochloride loaded chitosan nanoparticles for nose to brain delivery: Development, characterization and in vivo anti-Parkinson activity. Int J Biol Macromol. 109, 27-35 (2018).

105. Sridhar V, Pharm M, Gaud R, Bajaj A, Wairkar S. Pharmacokinetics and pharmacodynamics of intranasally administered selegiline nanoparticles with improved brain delivery in Parkinson's disease. Nanomedicine. 14(8), 26092618 (2018).

106. Axelsen TM, Woldbye DPD. Gene Therapy for Parkinson's Disease, An Update. J Parkinsons Dis. 8, 195-215 (2018).

107. Helmschrodt C, Höbel S, Schöniger S, et al. Polyethylenimine NanoparticleMediated siRNA Delivery to Reduce a -Synuclein Expression in a Model of Parkinson' s Disease. Mol Ther Nucleic Acid. 9, 57-68 (2017).

108. Gan L, Li Z, Lv Q, Huang W. Rabies Virus Glycoprotein (RVG29)-linked microRNA-124-loaded Polymeric Nanoparticles Inhibit Neuroinflammation in a Parkinson' s disease Model. Int J Pharm. In press, 118449 (2019). 
109. Saraiva C, Paiva J, Santos T, Ferreira L, Bernardino L. MicroRNA-124 loaded nanoparticles enhance brain repair in Parkinson' s disease. J Controlled Release. 235, 291-305 (2016).

110. Walker F. Huntington's disease. The Lancet. 369(9557), 218-228 (2007).

111. Roos RAC. Huntington' s disease : a clinical review. Orphanet J Rare Dis. 5(40), $1-8$ (2010).

112. Hsu Y, Chang Y, Chern Y. Insights into GABA A ergic system alteration in Huntington' s disease. Royal Soc Publish. 8, 180165 (2018).

113. Rawlins MD, Wexler NS, Wexler AR, et al. The Prevalence of Huntington's Disease. Neuroepidemiology. 46, 144-153 (2016).

114. Frank S, Testa CM, Stamler D, et al. Effect of Deutetrabenazine on Chorea Among Patients With Huntington Disease A Randomized Clinical Trial. JAMA. 316, 40-50 (2016).

115. Mestre TA. Recent advances in the therapeutic development for Huntington' disease. Parkinsonism Relat Disord. 59, 125-130 (2018).

116. Liu F-F, Luo J, Xiao-Yan D, Sun Y. Molecular Insight into the Inhibition Effect of Trehalose on the Nucleation and Elongation of Amyloid $\beta$-Peptide Oligomers. J Phys Chem B. 113(32), 11320-11329 (2009).

117. Tanaka M, Machida Y, Niu S, et al. Trehalose alleviates polyglutamine-mediated pathology in a mouse model of Huntington disease. Nat Med. 10(2), 148-154 (2004).

118. Debnath K, Pradhan N, Singh BK, Jana NR, Jana NR. Poly(trehalose) Nanoparticles Prevent Amyloid Aggregation and Suppress Polyglutamine Aggregation in a Huntington's Disease Model Mouse. ACS App Mater Interfaces. 9, 24126-24139 (2017).

119. Debnath K, Shekhar S, Kumar V, Jana NR, Jana NR. Efficient Inhibition of Protein Aggregation, Disintegration of Aggregates, and Lowering of Cytotoxicity by Green Tea Polyphenol-Based Self-Assembled Polymer Nanoparticles. ACS App Mater Interfaces.. 8, 20309-20318 (2016).

120. Valenza M, Chen JY, Paolo E Di, et al. Cholesterol-loaded nanoparticles ameliorate synaptic and cognitive function in Huntington's disease mice. EMBO Mol Med. 7(12), 1547-1564 (2015).

121. Godinho BMDC, Ogier JR, Darcy R, Driscoll CMO, Cryan JF. Self-assembling Modified $\beta$-Cyclodextrin Nanoparticles as Neuronal siRNA Delivery Vectors: Focus on Huntington' s Disease. Mol Pharm. 10, 640-649 (2013).

122. Adiele RC, Adiele CA. Metabolic defects in multiple sclerosis. Mitochondrion. 44, 7-14 (2019).

123. Chaudhuri A. Multiple sclerosis is primarily a neurodegenerative disease. $J$ Neural Transm. 120(10), 1463-1466 (2013).

124. Buesa-Estellez A, Cano-de-la-Cuerda R, Ortiz-Gutierrez RM, Palacios-Cena D. The impact of pharmacological treatment on patients with multiple sclerosis. Disabil Health J. In press, 1-7 (2019).

125. Stallone G, Infante B, Lorenzo A Di, Rascio F, Zaza G, Grandaliano G. mTOR inhibitors effects on regulatory T cells and on dendritic cells. J Transl Med. 14(1), 1-9 (2016).

126. LaMothe RA, Pallavi NK, Trinh V, et al. Tolerogenic nanoparticles induce antigen-specific regulatory $\mathrm{T}$ cells and Provide Therapeutic efficacy and Transferrable Tolerance against experimental autoimmune encephalomyelitis. Front Immunol. 9, 1-11 (2018).

127. Maldonado RA, Lamothe RA, Ferrari JD, Zhang A, Rossi RJ, Kolte PN. 
Polymeric synthetic nanoparticles for the induction of antigen-specific immunological tolerance. PNAS. 112(2), E156-165 (2015).

128. Kuo R, Saito E, Miller SD, Shea LD. Peptide-Conjugated Nanoparticles Reduce Positive Co-stimulatory Expression and T Cell Activity to Induce Tolerance. $\mathrm{Mol}$ Ther. 25(7), 1676-1685 (2017).

129. Pearson RM, Casey LM, Hughes KR, et al. Controlled Delivery of Single or Multiple Antigens in Tolerogenic Nanoparticles Using Peptide-Polymer Bioconjugates. Mol Ther. 25(7), 1655-1664 (2017).

130. Pei W, Wan X, Shahzad K, et al. Direct modulation of myelin-autoreactive CD4 + and CD8 + T cells in EAE mice by a tolerogenic nanoparticle co-carrying myelin peptide-loaded major histocompatibility complexes , CD47 and multiple regulatory molecules. Int J Nanomed. 13, 3731-3750 (2018).

131. Rittchen S, Boyd A, Burns A, et al. Myelin repair in vivo is increased by targeting oligodendrocyte precursor cells with nanoparticles encapsulating leukaemia inhibitory factor ( LIF ). Biomaterials. 56, 78-85 (2015).

132. Mohajeri M, Sadeghizadeh M, Naja F, Javan M. Polymerized nano-curcumin attenuates neurological symptoms in EAE model of multiple sclerosis through down regulation of inflammatory and oxidative processes and enhancing neuroprotection and myelin repair. Neuropharmacology. 99, 156-167 (2015).

133. Gammon JM, Tostanoski LH, Adapa AR, Chiu Y, Jewell CM. Controlled delivery of a metabolic modulator promotes regulatory $\mathrm{T}$ cells and restrains autoimmunity. J Controlled Release. 210, 169-178 (2015).

134. Kong F, Liu G, Zhou S, Guo J, Chen S, Wang Z. Superior transfection efficiency of phagocytic astrocytes by large chitosan / DNA nanoparticles. Int J Biol Macromol. 105, 1473-1481 (2017).

135. Cano A, Espina M, García M. Recent advances on anti-tumor agents-loaded polymeric and lipid based nano-carriers for the treatment of brain cancer. Current Pharm Des. Accepted (2020).

136. Aphios. Study of APH-1105 in Patients With Mild to Moderate Alzheimer's Disease [Internet]. (2020). Available from: https://clinicaltrials.gov/ct2/show/NCT03806478.

137. Rambam Health Care Campus. Exploratory Study Using Nanotechnology to Detect Biomarkers of Parkinson's Disease From Exhaled Breath [Internet]. (2012). Available from: https://clinicaltrials.gov/ct2/show/study/NCT01246336?term=nanoparticle\&cond $=$ Parkinson+Disease \&draw $=2 \&$ rank $=1$.

138. Clene Nanomedicine. 31P-MRS Imaging to Assess the Effects of CNM-Au8 on Impaired Neuronal Redox State in Parkinson's Disease (REPAIR-PD) [Internet]. 2020. Available from: https://clinicaltrials.gov/ct2/show/NCT03815916?term=nanoparticle\&cond=Park inson+Disease $\&$ draw $=2 \&$ rank $=2$.

139. Clene Nanomedicine. 31P-MRS Imaging to Assess the Effects of CNM-Au8 on Impaired Neuronal Redox State in Multiple Sclerosis (REPAIR-MS) [Internet]. (2020). Available from: https:/clinicaltrials.gov/ct2/show/NCT03993171?term=nanoparticle\&cond=Mult iple + Sclerosis\&draw $=2 \&$ rank $=3$.

140. National Institutes of Health Clinical Center. In Vivo Characterization of Inflammation With Ferumoxytol, an Ultrasmall Superparamagnetic Iron Oxide Nanoparticle, on 7 Tesla Magnetic Resonance Imaging. (2019). Available from: https://clinicaltrials.gov/ct2/show/NCT02511028?term=nanoparticle\&cond=Mult 
iple+Sclerosis\&draw $=2 \&$ rank $=1$.

141. Nagavarma BVN, Yadav HKS, Ayaz A, Vasudha LS, Shivakumar HG. Different techniques for preparation of polymeric nanoparticles- a review. Asian J Pharm Clin Res. 5(3), 16-23 (2012).

142. Attama AA, Momoh MA, Builders PF. Lipid Nanoparticulate Drug Delivery Systems : A Revolution in Dosage Form Design and Development. Recent Adv Nov Drug Carrier Syst. , 107-140 (2012).

143. Tapeinos C, Battaglini M, Ciofani G. Advances in the design of solid lipid nanoparticles and nanostructured lipid carriers for targeting brain diseases. $J$ Controlled Release. 264, 306-332 (2017). 